\title{
Rosmarinic acid exerts a neuroprotective effect on spinal cord injury by suppressing oxidative stress and inflammation via modulating the $\mathrm{Nrf} 2 / \mathrm{HO}-1$ and TLR4/NF-KB pathways
}

\author{
Zhanjun Ma ( $\square 974178036 @ q q . c o m$ ) \\ Lanzhou University Second Hospital \\ Yubao Lu \\ Lanzhou University
}

Fengguang Yang

Lanzhou University

Shaoping Li

Lanzhou University

Xuegang $\mathrm{He}$

Lanzhou University

\section{Yicheng Gao}

Lanzhou University

\section{Guangzhi Zahng}

Lanzhou University

\section{Enhui Ren}

Lanzhou University

\section{Yonggang Wang}

Lanzhou University Second Hospital

\section{Xuewen Kang}

Lanzhou University Second Hospital

\section{Research}

Keywords: Rosmarinic acid, Spinal cord injury, oxidative stress, inflammation, Nrf2/HO-1 pathway, TLR4/NF-KB pathway

Posted Date: November 11th, 2019

DOI: https://doi.org/10.21203/rs.2.17058/v1

License: (1) This work is licensed under a Creative Commons Attribution 4.0 International License. Read Full License 


\section{Abstract}

Background: Spinal cord injury ( $\mathrm{SCl})$ is a severe central nervous system injury for which few efficacious drugs are available. Rosmarinic acid (RA), a water-soluble polyphenolic phytochemical, has antioxidant, antiinflammatory, and anti-apoptotic properties. However, the effect of RA on SCl is unclear. We investigated the therapeutic effect and underlying mechanism of RA on $\mathrm{SCl}$ in vivo and in vitro.

Methods: In vivo experiment, The BBB locomotion scale, the inclined plane test, Nissl staining, and spinal cord edema were employed to determine the neuroprotective effects of RA treatment after SCl. Inflammatory and oxidative stress markers were detected by commercial kits and cell apoptosis status was measured by TUNEL staining. A proteomics and bioinformatics approach, together with Western blotting, was used to investigate the effect of RA on the proteome of $\mathrm{SCl}$ rats. In vitro experiment, oxidative stress and inflammatory injury were induced by $\mathrm{H} 2 \mathrm{O} 2$ and LPS stimulation. Effects of RA on cell viability, apoptosis, inflammatory, and oxidative stress were evaluated.

Results: Using a rat model of $\mathrm{SCl}$, we showed that RA improved locomotor recovery after $\mathrm{SCl}$ and significantly mitigated neurological deficit, increased neuronal preservation, and reduced apoptosis. Also, RA inhibited activation of microglia and the release of TNF-a, IL- 6 , and IL-1 $\beta$ and MDA. Moreover, proteomics analyses identified the Nrf2 and NF-KB pathways as targets of RA. Pretreatment with RA increased levels of Nrf2 and HO-1 and reduced those of TLR4 and MyD88 as well as phosphorylation of IkB and subsequent nuclear translocation of NF-KB-p65. Using H2O2- and LPS-induced PC12 cells, we found that RA ameliorated the $\mathrm{H} 2 \mathrm{O} 2$-induced decrease in viability and increase in apoptosis and oxidative injury by activating the Nrf2/HO-1 pathway. Also, LPS-induced cytotoxicity and increased apoptosis and inflammatory injury in PC-12 cells were mitigated by RA by inhibiting the TLR4/NF-KB pathway. The Nrf2 inhibitor ML385 weakened the effect of RA on oxidant stress, inflammation and apoptosis in $\mathrm{SCl}$ rats, and significantly increased the nuclear translocation of NF-KB.

Conclusions: Therefore, the neuroprotective effect on SCl of RA may be due to its antioxidant and antiinflammatory properties, which are mediated by modulation of the Nrf2/HO-1 and TLR4/NF-KB pathways. Moreover, RA activated Nrf2/HO-1, which amplified its inhibition of the NF-KB pathway.

\section{Introduction}

Spinal cord injury (SCl) is a severe type of central nervous system (CNS) injury that can cause spinal cord nerve cell death and glial scar formation [1]. Processes occurring after SCl result in motor, sensory, and autonomic dysfunction and neuralgia, which impose a heavy burden on patients' families and on society. The pathogenesis of $\mathrm{SCl}$ involves primary and secondary injury. Primary injury refers to the mechanical damage caused to the spinal nerves during trauma and irreversible vascular structural damage, axonal rupture, and nerve cell death. Secondary injury refers to ischemia-reperfusion injury, glutamate excitotoxicity, oxidative stress, intracellular calcium overload, neuronal apoptosis, and glial scar formation adjacent to the injury site [2, 3]. Secondary injury is caused mainly by inflammatory cell-mediated inflammatory reactions, which alter cell functions, promoting the death of residual nerve cells. The neuronal death caused by primary injury cannot be reversed [4]. Thus, much attention has focused on potential treatments for secondary injuries of SCl. 
Oxidative damage, inflammation, and apoptosis play important roles in extending secondary injury after SCl [5, 6]. Accordingly, antioxidant and anti-inflammatory factors are used therapeutically in SCl patients. Despite its high mortality rate, there is a lack of effective therapeutics for SCl. Natural products are an important source of new drugs for the treatment of neurological damage [7]. Medicinal plants have evolved antioxidants to cope with the reactive oxygen species (ROS) produced during photosynthesis [8]. Antioxidants from plant sources play important roles in maintaining human health. Indeed, plant components exhibited antioxidant activity in an SCl model [9]. Therefore, herbal antioxidants have therapeutic potential for SCl.

Rosmarinic acid (RA) is a water-soluble polyphenolic phytochemical derived from a variety of plant families such as Lamiaceae herbs, Boraginaceae, and the fern family Blechnaceae, which have antioxidant, antiinflammatory, anti-apoptotic, antitumor, and neuroprotective activities, implying therapeutic potential for various diseases [10-12]. RA is a natural antioxidant that can scavenge free radicals and oxidants. The protective effect of RA in a rat model of neuropathic pain was mediated by its antioxidant and antiinflammatory activities [13]. Furthermore, RA exerts powerful neuroprotective effects against Parkinson disease, Alzheimer disease, and cerebral ischemic diseases [14, 15]. Cui et al. reported that RA has antioxidant and anti-apoptotic properties that protect against ischemic stroke [16]; and RA showed a neuroprotective effect against $\mathrm{H}_{2} \mathrm{O}_{2}$-induced neuronal cell injury [17]. These findings prompted us to assess the therapeutic effects of RA on SCl. Although Shang et al. reported that RA can protect the spinal cord from injury [18], the roles and underlying molecular mechanisms of RA in SCl are unclear.

Nuclear factor erythroid-derived 2-related factor 2 (Nrf2) plays an important role in defense against oxidative stress and inflammation. Under normal physiological conditions, Nrf2 repressor Kelch-like ECH-associated protein 1 (Keap1) blocks Nrf2 and promotes its ubiquitination-proteasome degradation, thereby inhibiting its activation [19]. Upon oxidative stress or other cellular insult, Nrf2 is released from Keap1 and translocates into the nucleus, where it binds to antioxidant responsive element (ARE) promoters and activates the transcription of a battery of cytoprotective and antioxidant genes [20]. This triggers production of a series of endogenous enzymes, such as heme oxygenase-1 (HO-1), superoxide dismutase (SOD), and $\mathrm{NAD}(\mathrm{P}) \mathrm{H}$ quinoneoxidoreductase 1 (NQ01), to regulate oxidative stress, the inflammatory response, and apoptosis [21, 22]. $\mathrm{HO}-1$ is an important antioxidant regulated by Nrf2 that affects intracellular ROS levels in response to various stimuli. Activation of the $\mathrm{Nrf} / \mathrm{HO}-1$ pathway contributes to the prognosis after $\mathrm{SCl}[23,24]$. Furthermore, the Nrf2/HO-1 pathway ameliorates the inflammatory response and nuclear factor kappa beta (NF-KB) activation. It has been reported that Nrf2 KO mice have inflammation in multiple organs $[25,26]$. The anti-inflammatory effect of Nrf2/HO-1 is related to inactivation of the NF-KB pathway [26,27], and activation of this pathway following $\mathrm{SCl}$ modulates the release of proinflammatory cytokines in the CNS $[28,29]$. Therefore, pharmacological induction of the $\mathrm{Nrf2/HO}-1$ pathway might be a potent neuroprotective strategy for SCl.

We investigated the neuroprotective effect of RA on $\mathrm{SCl}$ and the underlying mechanisms in vivo and in vitro. The effects of RA on SCl-induced locomotor and neurological dysfunction, tissue structure integrity, and cellular apoptosis were evaluated, and its antioxidant and anti-inflammatory properties were assayed. A proteomics analysis indicated that RA exerted a neuroprotective effect in $\mathrm{SCl}$ by regulating the Nrf2 and NF-KB pathways. Next, the potential roles of the Nrf2/HO-1 and TLR4/NF-KB signaling pathways in the effect of RA 
on $\mathrm{SCl}$ were explored. The results enhance our understanding of the neuroprotective mechanisms of RA, which shows therapeutic promise for $\mathrm{SCl}$.

\section{Materials And Methods}

\section{Reagents and antibodies}

RA (purity $\geq 98 \%$ by HPLC) was obtained from Sigma-Aldrich (St. Louis, MO). Dulbecco's modified Eagle's medium with high glucose (DMEM/high glucose), fetal bovine serum (FBS), and antibiotics were obtained from Gibco/BRL (Gaithersburg, MD). The annexin V-fluorescein isothiocyanate (FITC)/propidium iodide (PI), LDH release, and ROS assay kits were obtained from Beyotime Co. (Hangzhou, China). The SOD, CAT, MDA, and GSH-Px assay kits were obtained from Nanjing Jiancheng Bioengineering Institute (Nanjing, China). The TNF-a, IL-6, IL-1 $\beta$, and IL-10 enzyme-linked immunosorbent assay (ELISA) kits were obtained from Yuanye Biotechnology (Shanghai, China). All reagents for two-dimensional electrophoresis (2-DE) were purchased from Bio-Rad Laboratories (Milan, Italy), and silver staining kits were purchased from CWBIO (Beijing, China). The Nrf-2 inhibitor (ML385) was purchased from Medchem Express (MCE Co. Ltd., Shanghai, China). Primary antibodies against GFAP, NeuN, NF-H, BDNF, Iba1, Nrf2, HO-1, TLR4, MyD88, IKBa, p-IKBa, IKKa/ $\beta$, p-IKKa/ $\beta$, and NF-kB p65 were purchased from Cell Signaling Technology (Danvers, MA). Antibodies against Bcl-2, Bax, caspase-9, caspase-3, TNF-a, IL-10, galectin-1, PRDX6, HSP70, ARG1, AKR1B1, ANXA2, HSP27, H3, and GAPDH were obtained from Proteintech Group Inc. (Chicago, IL). All other reagents were purchased from SigmaAldrich, unless specified otherwise.

\section{$\mathrm{SCl}$ model and drug administration}

Adult female Sprague-Dawley rats $(230 \pm 20 \mathrm{~g})$ were provided by the Experimental Animal Center of Lanzhou University. Animal care and experimental procedures were approved by the Animal Ethics Committee of Lanzhou University Second Hospital and performed according to the guidelines of the National Institutes of Health Guide for the Care and Use of Laboratory Animals. Before the experiment, the rats were adaptively fed for 7 successive days. All rats were kept under standard housing conditions $\left(22 \pm 3^{\circ} \mathrm{C}, 55 \pm 10 \%\right.$ humidity, and a 12/12 h light/dark cycle). Standard rodent chow and water were supplied ad libitum, and all efforts were made to reduce animal suffering. The rats were i.p. injected with $1 \%$ pentobarbital $(40 \mathrm{mg} / \mathrm{kg})$ before surgery to induce adequate analgesia. The animals were placed in the prone position. A 2-cm midline incision was made at the level of the T8-T10 vertebra, the paraspinal muscles were separated, and the T8-T10 spinal processes were removed. Laminectomy of ninth vertebra was performed to adequately expose the spinal cord. Next, a vascular clip (30 g force, Oscar, China) was used to compress the spinal cord for $30 \mathrm{~s}$ without destroying the dura mater, and the incision sites were sutured. The sham rats were subjected to the same surgery procedure except for compression injury. Bladder massage was performed twice a day to assist urination until micturition. RA (10,20, and $40 \mathrm{mg} / \mathrm{kg})$ was dissolved in normal saline (NS) and administered intraperitoneally (i.p.) daily for 7 or 14 consecutive days. Rats in the sham and $\mathrm{SCl}$ groups received an equivalent volume $(1 \mathrm{~mL})$ of $\mathrm{NS}$ as vehicle.

\section{In vivo experimental design}


The animal experiment was divided into two parts. In part 1, we evaluated the effect of RA on SCl rats and determined the mechanism (Fig. 1). Sixty female SD rats were randomly allocated into the sham, $\mathrm{SCl}, \mathrm{SCl}+10$ $\mathrm{mg} / \mathrm{kg} \mathrm{RA}, \mathrm{SCl}+20 \mathrm{mg} / \mathrm{kg} \mathrm{RA}$, and $\mathrm{SCl}+40 \mathrm{mg} / \mathrm{kg}$ RA groups ( $\mathrm{n}=12$ each). Six rats per group were euthanized for the neurological-function and histological studies. The remaining rats in each group $(n=6)$ were used for molecular biological and biochemical experiments. Rats in the sham and $\mathrm{SCl}$ groups were injected i.p. with NS, and rats in the three SCl + RA groups received i.p. injection of 10, 20, and $40 \mathrm{mg} / \mathrm{kg} \mathrm{RA}$, respectively, once per day for 14 successive days. At 7 days after $\mathrm{SCl}$, the rats were euthanized and the injured spinal cord lesions ( $6 \mathrm{~mm}$ around the center) were collected. The samples were rapidly fixed or frozen for further study. In part 2, we investigated the neuroprotective mechanism of RA on SCl. Sixty female SD rats were randomized into the sham, $\mathrm{SCl}, \mathrm{SCl}+\mathrm{RA}(20 \mathrm{mg} / \mathrm{kg}), \mathrm{SCl}+\mathrm{RA}(20 \mathrm{mg} / \mathrm{kg})+\mathrm{ML} 385(500 \mu \mathrm{g} / \mathrm{kg}$, inhibitor of $\mathrm{Nrf2})$, and $\mathrm{SCl}+\mathrm{ML} 385(500 \mu \mathrm{g} / \mathrm{kg})$ groups $(\mathrm{n}=12$ each). Rats in the sham and SCl groups were injected i.p. with NS, rats in the $\mathrm{SCl}+\mathrm{RA}+\mathrm{ML} 385$ group received i.p. injection of $20 \mathrm{mg} / \mathrm{kg}$ RA and intrathecal (i.t.) injection of $500 \mu \mathrm{g} / \mathrm{kg} \mathrm{ML385}$ (in DMSO) $1 \mathrm{~h}$ before administration of RA, and the rats in the SCl + RA and SCl

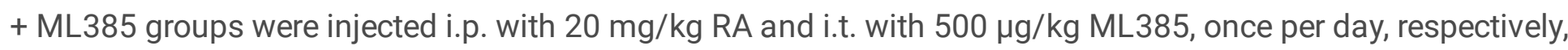
for 14 consecutive days. The rats were treated in the same manner as in part 1 .

\section{Assessment of locomotion recovery}

The Basso, Beattie, and Bresnahan (BBB) test was performed to determine whether RA improved recovery of locomotor function in rats subjected to $\mathrm{SCl}$ at days $1,3,5,7$ and 14 post-surgery [30]. The BBB scores ranged from 0 to 21, with a score of 21 representing normal locomotion and lower scores indicating impaired locomotor ability. The inclined plane test was performed as described previously [31]. The maximum angle at which a rat could maintain its position for $5 \mathrm{~s}$ without falling was recorded.

\section{Assessment of edema}

The water content of the spinal cord was determined using the wet weight/dry weight method. Briefly, rats were anesthetized and sacrificed, and the wet weight of the separated spinal cord was determined. The dry weight of the spinal cord was acquired after drying at $80^{\circ} \mathrm{C}$ for 2 days. Spinal cord water content was computed as follows: water content $(\%)=[$ (wet weight - dry weight $)$, wet weight $] \times 100 \%$.

\section{Hematoxylin and eosin and Nissl staining}

Rats were anesthetized and transcardially perfused with $0.9 \% \mathrm{NaCl}$ at 7 days following SCl. The spinal cord tissues near the lesion center were carefully collected, fixed in $4 \%$ paraformaldehyde (PFA) for $24 \mathrm{~h}$, and embedded in paraffin for transverse sectioning. Transverse sections ( $4 \mu \mathrm{m}$ thickness) were prepared on poly-Llysine-coated slides for histopathological analysis by hematoxylin \& eosin (H\&E) and Nissl staining according to the manufacturers' instructions. Images were captured under a light microscope (Nikon, Tokyo, Japan). The numbers of surviving neurons were determined using Image $\mathrm{J}$ software.

\section{Terminal deoxynucleotidyl transferase dUTP nickend labeling}

The apoptosis rate of the injured spinal cord was assayed by one-step terminal deoxynucleotidyl transferase dUTP nick-end labeling (TUNEL) at day 7 after SCl in accordance with the manufacturer's instructions (Beyotime Co., Hangzhou, China). Images were obtained using a fluorescence microscope (Olympus; 
Yokohama, Japan). The average number of TUNEL-positive cells in five randomly chosen fields of view per section was calculated using Image $\mathrm{J}$ software.

\section{2-DE and imaging analyses}

The 2-DE analysis was performed as described previously [32,33]. Briefly, $100 \mathrm{mg}$ of spinal cord tissue (SCI group and $\mathrm{SCl}+20 \mathrm{mg} / \mathrm{kg}$ RA group) were harvested and lysed in $1 \mathrm{~mL}$ of lysis buffer. Whole-cell lysates (80 $\mu \mathrm{g}$ ) were added to a 17-cm immobilized pH 3-10 nonlinear gradient strip (Bio-Rad Laboratories) and rehydrated in an Ettan IPG-phor isoelectric focusing system (Bio-Rad) at $20^{\circ} \mathrm{C}$ and $30 \mathrm{~V}$ for $10 \mathrm{~h}$. Sample uptake into the strip was achieved at $20^{\circ} \mathrm{C}$ using the following settings: $250 \mathrm{~V}$ for $30 \mathrm{~min}, 1,000 \mathrm{~V}$ for $1 \mathrm{~h}$, and $500 \mathrm{~V}$ for $10 \mathrm{~h}$. Next, the strips were incubated in equilibration buffer containing $1 \%(\mathrm{w} / \mathrm{v})$ dithiothreitol and $2.5 \%(\mathrm{w} / \mathrm{v})$ iodoacetamide in $6 \mathrm{M}$ urea, $0.375 \mathrm{M}$ Tris- $\mathrm{HCl}(\mathrm{pH} 8.8), 20 \%$ glycerol, and $2 \%$ sodium dodecyl sulfate (SDS). The second-dimension separation was performed using $12 \%$ SDS-polyacrylamide gel electrophoresis (PAGE) in two steps at $10^{\circ} \mathrm{C}: 70 \mathrm{~V} / \mathrm{gel}$ for $30 \mathrm{~min}$ and $300 \mathrm{~V} / \mathrm{gel}$ until the bromophenol blue reached the bottom of the gel. The gels were stained using a silver staining kit (CWBIO), spots were detected using a GS-800 calibrated densitometer (Bio-Rad Laboratories), and the images were analyzed using PDQuest ${ }^{\mathrm{TM}}$ 2-DE (ver. 8.0.1; Bio-Rad Laboratories). Protein spots were extracted from the 2-DE gels and identified by MALDI-TOF/MS, and protein-protein interaction network and gene ontology $(\mathrm{GO})$ analyses of differential proteins were performed as described previously [32, 33].

\section{Cell culture and experimental design in vitro}

PC12 cells originate from a rat adrenal pheochromocytoma cell line, have neuron-like characteristics, and have been used for $\mathrm{SCl}$ research in vitro [34, 35]. PC12 cells were obtained from the Cell Bank of the Chinese Academy of Sciences (Shanghai, China) and cultured in high-glucose Dulbecco's modified Eagle's medium (DMEM; Thermo Fisher Scientific, Waltham, MA) supplemented with $10 \%$ fetal bovine serum (FBS; Gibco; Thermo Fisher Scientific) and $1 \%$ penicillin/streptomycin (Gibco) at $37^{\circ} \mathrm{C}$ in a humidified atmosphere with $5 \%$ $\mathrm{CO}_{2}$. The experiment was divided into two parts. In part 1, we investigated whether RA protects against $\mathrm{H}_{2} \mathrm{O}_{2}{ }^{-}$ induced oxidative injury in PC12 cells. PC12 cells in logarithmic phase were allocated into the control, $\mathrm{H}_{2} \mathrm{O}_{2}$, and $\mathrm{RA}(5,10$, and $20 \mu \mathrm{g} / \mathrm{mL})$ groups. In the control group, cells were treated with normal medium, and those in the $\mathrm{H}_{2} \mathrm{O}_{2}$ group were treated with $200 \mu \mathrm{M} \mathrm{H}_{2} \mathrm{O}_{2}$. Cells in the RA group were pretreated with RA for $24 \mathrm{~h}$ and subsequently with $200 \mu \mathrm{M} \mathrm{H}_{2} \mathrm{O}_{2}$ for $24 \mathrm{~h}$. In part 2, we assessed the protective effect of RA on LPS-induced inflammatory injury in PC12 cells. PC12 cells were allocated into the control, LPS, and RA $(5,10$, and 20 $\mu \mathrm{g} / \mathrm{mL}$ ) groups. Control cells were treated only with normal medium, and LPS-injury cells were treated with LPS $(5 \mu \mathrm{g} / \mathrm{mL})$ for $12 \mathrm{~h}$. PC12 cells in the RA groups were pretreated with various concentrations of RA for 24 $\mathrm{h}$ prior to exposure to LPS $(5 \mu \mathrm{g} / \mathrm{mL})$ for $12 \mathrm{~h}$.

\section{Cell viability assay}

The viability of PC12 cells was determined by a Cell Counting Kit-8 (CCK-8) assay. In brief, PC12 cells were seeded onto 96 -well plates $\left(5 \times 10^{3}\right.$ per well) containing $100 \mu \mathrm{L}$ of complete medium for $24 \mathrm{~h}$. Next, $10 \mu \mathrm{L}$ of CCK-8 (Beyotime; Jiangsu, China) solution was added to each well, and the plate was incubated at $37^{\circ} \mathrm{C}$ for 2 h. Finally, absorbance at $450 \mathrm{~nm}$ was measured using a microplate reader (Bio-Rad; Hercules, CA). 


\section{Lactate dehydrogenase release assay}

A lactate dehydrogenase (LDH) release assay was used to evaluate cytotoxicity by detecting the content of LDH in culture supernatant. Medium was harvested and the LDH content was determined using an LDH release assay kit (Beyotime; Jiangsu, China) according to the manufacturer's protocol. Absorbance at $450 \mathrm{~nm}$ was measured using a microplate reader.

\section{Annexin V-fluorescein isothiocyanate/propidium iodide assays of apoptosis}

To assess apoptosis, the PC12 cells $\left(1 \times 10^{5}\right.$ per well) were seeded onto six-well plates for $24 \mathrm{~h}$. The cells were harvested, washed twice with PBS, resuspended in $195 \mu \mathrm{L}$ of binding buffer containing annexin V-FITC $(5 \mu \mathrm{L})$ and propidium iodide (PI; $10 \mu \mathrm{L})$ using an apoptosis assay kit (Beyotime; Jiangsu, China), and incubated in the dark for $15 \mathrm{~min}$. The apoptosis rate was analyzed by flow cytometry (BD Biosciences; Piscataway, NJ).

\section{Measurement of reactive oxygen species concentration}

The intracellular reactive oxygen species (ROS) concentration was measured using an ROS assay kit with dichloro-dihydro-fluorescein diacetate (DCFH-DA, Beyotime), which is oxidized to fluorescent DCF by hydroperoxides. Cells were collected, resuspended in PBS, and stained with DCFH-DA according to the manufacturer's directions. The level of ROS was determined by flow cytometry.

\section{Detection of cytokine expression and oxidative stress markers}

The collected spinal cord tissue was thawed, weighed, and dissolved in $1 \mathrm{~mL}$ of $0.9 \%$ normal saline at $4^{\circ} \mathrm{C}$, and the homogenate was obtained by centrifugation at $10000 \mathrm{~g}$ for $15 \mathrm{~min}$. Next, the levels of inflammatory factors (TNF-a, IL-6, IL-1 $\beta$, and IL-10) in spinal cord supernatant and PC12 cell culture supernatant were assayed using ELISA kits according to the manufacturers' instructions (Yuanye Biotechnology, Shanghai, China). Absorbance at $450 \mathrm{~nm}$ was measured using a microplate reader.

Biochemical kits (Beyotime; Jiangsu, China) were used to determine the level of superoxide dismutase (SOD), glutathione peroxidase (GSH-Px), catalase (CAT), and malondialdehyde (MDA) in the supernatant of perilesional spinal cord tissue and PC12 cells according to the manufacturer's instructions. Protein contents were measured using a bicinchoninic acid (BCA) assay kit (Beyotime).

\section{Immunofluorescence staining}

At 7 days after surgery, spinal cord tissue was embedded in paraffin. Transverse sections ( $4 \mu \mathrm{m}$ thick) were cut, deparaffinized in xylene, and rehydrated in a graded series of ethanol. The cells were cultured on $12 \times 12-$ $\mathrm{mm}$ microscopic glasses and fixed in 4\% PFA. Tissues and cells were incubated with $5 \%$ bovine serum albumin (BSA) for $1 \mathrm{~h}$, incubated with anti-GFAP (1:500), -NeuN (1:500), -lba1 (1:300), -caspase-3 (1:500), -HO1 (1:200), and anti-p65 (1:500) primary antibodies at $4^{\circ} \mathrm{C}$ overnight, and with the appropriate secondary antibodies for $1 \mathrm{~h}$. Nuclei were counterstained with 4'-6-diamidino-2-phenylindole for 10 min, and the slides were washed three times in PBS and photographed under a fluorescence microscope.

\section{Quantitative real time RT-PCR}


Total RNA was isolated from spinal cord tissue and PC12 cells using TRIzol ${ }^{\mathrm{TM}}$ reagent (Qiagen; Valencia, CA) according to the manufacturer's instructions. Complementary DNA (cDNA) was synthesized from $1 \mu \mathrm{g}$ of total RNA using a cDNA reverse transcription kit (TaKaRa; Dalian, China) according to the manufacturer's instructions. mRNA levels were assayed by reverse transcription quantitative polymerase chain reaction (RTqPCR) following a standard protocol with the LightCycler 96 System (Roche; Pleasanton, CA) and detection via SYBR green (SYBR Green Supermix; TaKaRa). The results were normalized to the GAPDH mRNA level and foldchanges were analyzed using the $2^{-\Delta \Delta C t}$ method. The sequences of the primers are listed in Table 1.

\section{Western blotting}

Spinal cord tissues and cells were washed twice with cold PBS, lysed in radioimmunoprecipitation assay buffer, and protein levels were quantified using a Bradford Protein Assay Kit (Beyotime; Hangzhou, China). Equal amounts of protein samples were subjected to $10 \%$ SDS-PAGE, electro-transferred onto a $0.45-\mu \mathrm{m}$ polyvinylidene difluoride membrane (Millipore; Billerica, MA), blocked in Tris-buffered saline with Tween 20 containing 5\% BSA for $2 \mathrm{~h}$ at room temperature, and incubated overnight with the primary antibodies at $4{ }^{\circ} \mathrm{C}$. Next, the membranes were incubated with the corresponding secondary antibodies for $1 \mathrm{~h}$ and signals were visualized by chemiluminescence (Bio-Rad). Image $\mathrm{J}$ software was used to analyze the Western blotting data.

\section{Statistical analysis}

Values are means \pm standard deviation (SD) of triplicate experiments. Student's $t$-test and one-way analysis of variance were performed with Statistical Package for the Social Sciences ver. 21.0 software (IBM Corporation, Chicago, IL) to assess the significance of differences; $p$-values of $<0.05$ were considered to indicate statistical significance.

\section{Results}

\section{RA protected spinal cord tissue and improved functional recovery from SCl}

The chemical structure of RA is presented in Fig. 2A. To explore the therapeutic effect of RA on locomotion recovery after $\mathrm{SCl}$, we performed $\mathrm{BBB}$ and inclined plane testing at 2 weeks after injury. The mean BBB score of the sham group was 21, and those of the SCI and RA-treated groups were below normal (Fig. 2B). At 3 days after injury, there was no significant difference in BBB scores between the SCI and RA treatment groups. At 5 days after injury, BBB scores were higher in the RA-treated group compared to the untreated group. Inclinedplane test scores were consistently higher in the RA-treated group at 5, 7, and 14 days after injury (Fig. 2C). Compared with the sham group, the water content of the SCI group increased significantly at day 7 after injury but was markedly decreased by RA (Fig. 2D). Furthermore, HE staining at day 7 showed large areas of hemorrhage, swelling and destruction of nerve cells, widening of interstitial space, glial cells proliferation, and infiltration of inflammatory cells in the SCI group; these pathologies were significantly improved by RA (Fig. 2E). Moreover, RA significantly increased the number of Nissl-positive neurons at 7 days after injury in a dosedependent manner (Fig. 2F-G). Therefore, RA promoted functional recovery and ameliorated tissue damage in $\mathrm{SCl}$ rats.

\section{RA increased neurotrophin expression in $\mathrm{SCl}$ rats}


Immunofluorescence staining showed that levels of GFAP, a marker of astrocytes, increased in the SCI group, suggesting activation of astrocytes; this increase was markedly attenuated by RA (Fig. 3A, C).

Immunofluorescence staining demonstrated that numbers of NeuN-positive cells were significantly lower in the $\mathrm{SCl}$ group than in the sham group. Notably, RA significantly increased the number of NeuN-positive cells compared with the $\mathrm{SCl}$ group (Fig. 3B-C). Moreover, the results of Western blotting and immunofluorescence for GFAP and NeuN were consistent. The levels of NF-H and BDNF were increased by RA compared with the SCl group (Fig. 3D-E). Therefore, RA increased the expression of neurotrophic factors in the spinal cord, possibly promoting positive the neurological outcomes after $\mathrm{SCl}$.

\section{RA suppressed cell apoptosis in the spinal cord of $\mathrm{SCl}$ rats}

To evaluate the effect of RA on apoptosis, TUNEL staining was performed at day 7 after SCI. TUNEL-positive cells were detected at the injury site in the spinal cord of $\mathrm{SCl}$ rats, RA decreased the number of apoptotic cells in a dose-dependent manner (Fig. 4A). We next assayed the levels of apoptosis-related proteins.

Immunohistochemistry staining indicated that the number of cleaved caspase-3-positive cells in the spinal cord was increased in the SCl rats and was decreased by RA (Fig. 4B). Additionally, Western blotting showed that levels of Bax, cleaved caspase-9, and cleaved caspase-3 were upregulated in the spinal cord of SCl rats compared to sham rats, while that of Bcl-2 was markedly downregulated. Notably, RA reduced Bax, cleaved caspase-9, and cleaved caspase-3 levels and increased the Bcl-2 level, significantly (Fig. 4C). Therefore, RA inhibited apoptosis in spinal cord tissue after SCl.

\section{RA attenuated oxidative stress in the spinal cord of SCI rats}

To investigate the effects of RA on oxidative stress in SCI rats, changes in SOD, CAT, and GSH-Px activities and the MDA content of spinal cord tissue were assayed. The activities of SOD (Fig. 5A), CAT (Fig. 5B), and GSH-Px (Fig. 5C) were significantly decreased and the content of MDA (Fig. 5D) was significantly increased in the SCI group compared to the sham group. RA markedly increased the activities of SOD, CAT, and GSH-Px and decreased the content of MDA, implying attenuation of SCl-induced oxidative damage.

\section{RA inhibited the inflammatory response in the spinal cord of SCl rats}

The inflammatory response plays an important role in the pathogenesis of $\mathrm{SCl}$. An increased number of microglia and their activation is critical in the development of inflammation following $\mathrm{SCl}$, so we performed immunofluorescence staining for Iba-1 (microglia marker) on spinal cord tissue at 7 days after $\mathrm{SCl}$ with and without treatment with $20 \mathrm{mg} / \mathrm{kg}$ RA. A few Iba-1-positive cells were observed in the sham group, while more Iba-1-positive cells were present in the injured spinal cord tissue at 7 days after $\mathrm{SCl}$. The number of Iba-1positive cells was reduced by $20 \mathrm{mg} / \mathrm{kg}$ RA (Fig. 6A-B). Therefore, RA significantly inhibited microglial activation in SCl. Next, ELISA showed that the levels of TNF-a, IL-6, and IL-1 $\beta$ in the SCl group were significantly increased compared with the sham group, indicating excessive inflammation. RA significantly reduced the levels of TNF-a, IL-6, and IL-1 $\beta$ and significantly increased that of IL-10 compared to the SCl group (Fig. 6C-F). Furthermore, Western blotting and RT-PCR showed that the rats in the SCl group had higher TNF-a and IL-10 protein and mRNA levels compared with the sham rats. Also, the TNF-a level was significantly reduced and that of IL-10 was increased by RA (Fig. 6G-H). Therefore, RA inhibited the inflammatory response in the spinal cord of $\mathrm{SCl}$ rats. 


\section{Proteomics analysis}

We performed proteomics analyses on spinal cord tissue at 7 days after $\mathrm{SCl}$ with and without $20 \mathrm{mg} / \mathrm{kg} \mathrm{RA}$. $\mathrm{SCl}$ rats were treated with $20 \mathrm{mg} / \mathrm{kg}$ RA for 7 days, spinal cord tissue was harvested, and proteins were resolved by 2D-PAGE (Fig. 7A). The 16 proteins that showed at least a twofold difference in intensity between the RA-treated $\mathrm{SCl}$ rats and $\mathrm{SCl}$ rats $(p<0.05)$ were subjected to further analysis.

The identified proteins-with their theoretical molecular weights, isoelectric points (pl), coverage, MASCOT scores, MS/MS matched sequences, and changes in levels-are listed in Table 2. Of them, 10 were upregulated (galectin-1 [Gal-1], ubiquitin carboxyl-terminal hydrolase isozyme L1 [UCHL1], peroxiredoxin- 6 [PRDX6], fatty acid-binding protein, brain [FABP2]), serotransferrin [TF], heme oxygenase 1 [HO-1], heat shock $70 \mathrm{kDa}$ protein 1A [HSPA1A], neurofilament light polypeptide [NEFL], neurofilament medium polypeptide (NEFM), and arginase-1 [ARG1]), and 6 were downregulated (peripheral myelin protein 22 [PMP22], annexin A2 [ANXA2], aldose reductase [AKR1B1], cathepsin B [CTSB], heat shock $27 \mathrm{kDa}$ protein 1 [HSP27], and peroxiredoxin 1 [PRDX1]). Western blotting confirmed the differential levels of galectin-1, PRDX6, HSP70, ARG1, AKR1B1, ANXA2, and HSP27 in the spinal cord tissue of RA-treated and -untreated SCI rats. RA upregulated galectin-1, PRDX6, HSP70, and ARG1 levels and downregulated AKR1B1, ANXA2, and HSP27 levels compared with the $\mathrm{SCl}$ group (Fig. 7B). The 2-DE and Western blot analyses yielded similar results.

The online STRING database was used to forecast the interaction networks among the identified proteins (Fig. 7C); HO-1, HSP90, HSP27, and ANXA2 were key nodes and modulators in the network. GO analysis is a dynamic, controlled vocabulary for the role of genes and proteins in eukaryotic cells. A GO analysis revealed that 17 functions were annotated as MF, 287 as BP, and 69 as CC $(p<0.05)$; the top 10 significantly enriched GO terms (threshold false discovery rate $p<0.01$ ) are shown in Fig. 7D-F. A reactome pathway analysis showed that proteins were enriched in the neutrophil degranulation, detoxification of ROS, iron uptake and transport, cellular responses to stress, post-translational protein phosphorylation, and regulation of insulin-like growth factor (IGF) transport pathways (Fig. 7G). The identified proteins are involved in multiple biological processes and have molecular functions mainly related to energy metabolism, heat shock/stress, oxidative stress, inflammation, and apoptosis. Therefore, the neuroprotective effect of RA on SCl is mediated by improvement of energy metabolism and prevention of oxidative stress and inflammation.

\section{RA modulated the Nrf2/HO-1 and TLR4/NF-KB pathways in the spinal cord of SCl rats}

In the STRING analysis, HO-1 was a key node and modulator in the identified network. HO-1 is an antioxidant enzyme downstream of the Nrf2 signaling pathway. Also, HSP27, ANXA2, AKR1B1, and ARG1 are closely related to the NF-KB signaling pathway. Thus, we investigated the effect of RA on the Nrf2 and NF-KB signaling pathways. Compared with the sham and $\mathrm{SCl}$ groups, cytoplasmic and nuclear Nrf2 levels were significantly decreased and increased, respectively, by RA (Fig. 8A). We next assayed levels of HO-1, an antioxidant enzyme regulated by Nrf2. RA increased the expression of HO-1 compared to the untreated group (Fig. 8A). Also, RA increased the Nrf2 and HO-1 mRNA levels in injured tissue compared to the untreated group (Fig. 8B). Therefore, RA promoted nuclear translocation of Nrf2 and increased expression of HO-1.

TLR4/NF-KB is a key transcription factor that triggers expression of proinflammatory cytokines. The levels of TLR4, MyD88, p-IKBa, and p-IKKa/ $\beta$ were significantly increased in the $\mathrm{SCl}$ group; this effect was significantly 
reversed by RA (Fig. $\mathbf{8 C}$ ). Compared to the $\mathrm{SCl}$ group, pretreatment with RA reduced nuclear translocation of NF-KB-p65 (Fig. 8D). Therefore, RA inhibited inflammation by downregulating levels of TLR4, MyD88, p-IkBa, p$\mathrm{IKKa} / \beta$, and NF-KB-p65 (nucleus) and upregulating that of NF-KB-p65 (cytoplasm).

\section{RA attenuated $\mathrm{H}_{2} \mathrm{O}_{2}$-induced oxidative injury and activated the Nrf2/HO-1 pathway in PC12 cells}

To confirm the effects of RA on oxidative stress in vitro, PC12 cells were treated with $\mathrm{H}_{2} \mathrm{O}_{2}$ followed by RA. Treatment with RA at 5,10 , and $20 \mu \mathrm{g} / \mathrm{mL}$ for $24 \mathrm{~h}$ did not cause any apparent cytotoxicity in PC12 cells, while 40 or $80 \mu \mathrm{g} / \mathrm{mL}$ RA decreased PC-12 cell viability (Supp. Fig. 1). Therefore, we used $\leq 20 \mu \mathrm{g} / \mathrm{mL}$ RA in subsequent experiments. A CCK-8 assay showed that $\mathrm{H}_{2} \mathrm{O}_{2}(200 \mu \mathrm{M})$ treatment for $24 \mathrm{~h}$ decreased the viability of PC12 cells; this effect was reversed by pretreatment with RA for $24 \mathrm{~h}$ (Fig. 9A). The release of LDH, an indicator of cytotoxicity, was used to estimate the protective effect of RA. The LDH level in the culture medium of $\mathrm{H}_{2} \mathrm{O}_{2}$-treated cells was significantly increased compared with that of control cells. RA significantly decreased LDH release from cells in a dose-dependent manner (Fig. 9B). The proportion of apoptotic cells was decreased by 5,10 , and $20 \mu \mathrm{g} / \mathrm{mL}$ RA compared with the $\mathrm{H}_{2} \mathrm{O}_{2}$ group (Fig. 9C). Likewise, RA reversed $\mathrm{H}_{2} \mathrm{O}_{2}$ induced alterations in the levels of apoptosis-associated proteins (Fig. 9D). Immunofluorescence staining demonstrated that RA pretreatment significantly decreased the number of cleaved caspase-3-positive cells compared with the $\mathrm{H}_{2} \mathrm{O}_{2}$ group (Supp. Fig. 2). Also, the increased fluorescence intensity suggested intracellular accumulation of ROS in $\mathrm{PC} 12$ cells exposed to $\mathrm{H}_{2} \mathrm{O}_{2}$ compared to the control (Fig. 9E). However, pretreatment of PC12 cells with RA prior to $\mathrm{H}_{2} \mathrm{O}_{2}$ exposure attenuated the fluorescence intensity, indicating inhibition of ROS generation. Compared to the $\mathrm{H}_{2} \mathrm{O}_{2}$ group, cells pretreated with RA exhibited a decreased level of MDA but increased activities of SOD, GSH-Px, and CAT (Fig. 9F). Furthermore, nuclear Nrf2 and HO-1 levels were increased and cytoplasmic Nrf2 levels were decreased by RA in $\mathrm{H}_{2} \mathrm{O}_{2}$-induced-PC12 cells (Fig. 9G). Immunofluorescence staining demonstrated that RA pretreatment significantly increased the number of HO-1positive cells compared with the $\mathrm{H}_{2} \mathrm{O}_{2}$ group (Fig. $\left.9 \mathrm{H}-\mathrm{I}\right)$. Therefore, RA increased cell viability, reduced oxidative stress, and suppressed apoptosis in the presence of $\mathrm{H}_{2} \mathrm{O}_{2}$-induced oxidative injury by activating the $\mathrm{Nrf} 2 / \mathrm{HO}-1$ signaling pathway.

\section{RA attenuated LPS-induced inflammatory injury and inhibited the NF-KB pathway in PC12 cells}

To verify the involvement of the NF-KB pathway in RA-mediated inhibition of inflammation in vitro, neuronal PC1 2 cells were treated with LPS followed by RA. A CCK-8 assay indicated that pretreatment of PC12 cells with 5,10 , and $20 \mu \mathrm{g} / \mathrm{mL}$ RA significantly ameliorated the LPS-induced reduction in their viability (Fig. 10A). Also, RA significantly suppressed LPS-induced cytotoxicity and apoptosis, as evidenced by decreased LDH release (Fig. 10B), upregulation of Bcl-2, and downregulation of Bax, cleaved caspase-3, and cleaved caspase-9 (Fig. 10C). Also, immunofluorescence staining showed that RA pretreatment significantly reduced the number of cleaved caspase-3-positive cells compared with the LPS group (Supp. Fig. 3). The levels of TNF-a, IL-6, and IL$1 \beta$ were significantly decreased and that of IL-10 was increased by RA pretreatment (Fig. 10D). The levels of TNF- $\alpha$ and IL-10 mirrored these results (Fig. 10E). The marked increase in the TLR4, MyD88 and phosphorylated IKBa and IKKa/ $\beta$ levels indicated activation of the NF-KB pathway in LPS-induced PC1 2 cells. However, RA decreased the expression of TLR4, MyD88, p-IKBa, and p-IKKa/ $\beta$ (Fig. 10F). Compared to the LPS group, pretreatment with RA reduced the nuclear translocation of p65 (Fig. 10G). Also, immunofluorescence

Page $11 / 36$ 
staining showed that RA significantly reduced the number of NF-KB p65-positive cells compared with the LPS group (Fig. 10H-I). Therefore, RA exerted anti-apoptotic and anti-inflammatory effects on LPS-injured PC12 cells by suppressing the TLR4/NF-KB signaling pathway.

\section{ML385 reversed the effects of RA on SCI}

To verify involvement of the Nrf2 signaling pathway in the neuroprotective effect of RA on SCl, an Nrf2 inhibitor (ML385) was used. The BBB scores and inclined-plane test revealed that the effects of RA were significantly inhibited by ML385 at days 7 and 14 (Fig. 11A-D). ML385 significantly increased the water content of spinal cord tissue at day 7 post-injury under the SCI plus RA condition (Fig. 11E). Moreover, HE staining revealed that ML385 significantly increased injury of single RA treatment (Fig. 11F). The effects of combined treatment with RA and ML385 on neuronal survival were assayed by Nissl staining; the combination decreased the number of surviving neurons in the anterior horn (Fig. 11G-H). Furthermore, TUNEL staining showed that the number of apoptotic cells was decreased significantly by RA; this effect was reversed by ML385 (Fig. 111). Also, SCl-mediated apoptosis was diminished by RA (as determined by assaying the levels of Bcl-2, Bax, cleaved caspase-9, and cleaved caspase-3); this effect was reversed by ML385 (Fig. 11J). Therefore, RA activated the Nrf2 signaling pathway to promote functional recovery and inhibit apoptosis in $\mathrm{SCl}$.

\section{RA exerted a neuroprotective effect by modulating the Nrf2 and NF-KB pathways}

Next, we explored the effect of RA on SCl-induced oxidative stress and inflammation after inhibiting the Nrf2 signaling pathway. The SCl-mediated decrease in SOD, CAT, and GSH-Px activity and increase in the MDA content were attenuated by RA; this effect was significantly diminished by ML385 (Fig. 12A). The levels of proinflammatory cytokines (TNF-a, IL-6, and IL-1 $\beta$ ) were significantly decreased and that of the antiinflammatory cytokine IL-10 was increased by RA pretreatment, and the anti-inflammatory activity of RA was significantly reduced by ML385 (Fig. 12B). Similar results were observed for the protein levels of TNF-a and IL10 (Fig. 12C). Western blotting showed that nuclear Nrf2 and HO-1 levels were significantly decreased and cytoplasmic Nrf2 levels were increased by ML385 under the SCI plus RA condition (Fig. 12D). Moreover, Western blotting indicated that administration of RA alone significantly reduced expression of $\mathrm{p}-\mathrm{I} \mathrm{KB}$ and $\mathrm{p}$ $\mathrm{IKKa} / \beta$ compared to the $\mathrm{SCl}$ group; this was abrogated by ML385 (Fig. 12E). Also, expression of p65 (nucleus) was increased and that of p65 (cytoplasmic) was significantly increased by ML385 under the SCI plus RA condition (Fig. 12F). Therefore, RA inhibited the NF-KB signaling pathway indirectly by activating the Nrf2 signaling pathway. The above results indicate that RA protected $\mathrm{SCl}$ rats against oxidant stress and inflammation by activating the Nrf2 signaling pathway and inhibiting the NF-KB signaling pathway.

\section{Discussion}

Traumatic SCl is a major cause of death and long-term paralysis worldwide [36]. SCl patients frequently have severe physical activity disorders, placing a heavy burden on families and society. However, currently available drugs, surgery, and other therapies have limited efficacy and various adverse effects. Most traumatic SCl does not involve physical transection of the spinal cord, but damage to the spinal cord due to contusion, compression, or traction injury. Such incomplete $\mathrm{SCl}$ can cause persistent severe secondary damage, which 
can be treated [37]. Therefore, preservation of living cells during secondary injury is a major therapeutic target for SCl. Plant-derived drugs for $\mathrm{SCl}$ are safe, effective, and have few side effects [7]. RA is a polyphenolic phytochemical extracted from a range of Labiatae herbs with powerful antioxidant, anti-inflammatory, and neuroprotective effects in vitro and in vivo [13-17]. We evaluated the ability of RA to promote functional recovery from SCl. The results demonstrate that RA activates the $\mathrm{Nrf} / \mathrm{HO}-1$ pathway and inhibits the TLR4/NF-KB pathway to reduce oxidant stress, inflammation, and apoptosis, thereby ameliorating the reduced locomotor function and tissue damage of acute SCl (Fig. 13)..

Evaluation of neurologic function is necessary for assessment of recovery from SCl. We performed BBB and inclined-plane tests to assess the locomotor function of $\mathrm{SCl}$ rats. RA remarkably improved locomotor function recovery, ameliorated tissue damage, and reduced the water content ratio in the $\mathrm{SCl}$ rats. Neuronal injury plays a key role in the progression and prognosis of acute SCl. The number of Nissl bodies was significantly reduced in the $\mathrm{SCl}$ rats. Nissl bodies comprise rough endoplasmic reticulum of synthetic proteins that reflect the neural structures of the brain and spinal cord and are related to the nutritional status of neurons; they may dissolve or even disappear under pathological conditions. Similarly, decreased density of NeuN-positive cells indicates loss of neurons in $\mathrm{SCl}$. BDNF is a neurotrophic factor that regulates the growth and differentiation of neurons during development and the plasticity and survival of adult neurons and glial cells [38]. NF is a neuron-specific intermediate filament protein and a major neuron-specific protein and cytoskeleton that plays an important role in preserving the spatial configuration of nerve cells and signal transduction and is closely related to axon regeneration [39]. Astrocytes are the most abundant type of glial cell in the CNS and actively participate in neuropathological responses. Astrocytes typically proliferate in response to $\mathrm{SCl}$. Activated astrocytes produce a series of proinflammatory cytokines, which regulate neuroinflammatory responses. In addition, astrocytes produce chemokines that attract inflammatory cells through the blood-brain barrier [40]. Inflammatory activation of astrocytes leads to the formation of dense scars that affect the regeneration of axons [41]. RA prevented neuron loss and promoted neuronal regeneration, as indicated by an increase in the number of Nissl bodies and the expression of NeuN, BDNF, and NF-H, and abolition of astrocyte activation.

Neuronal death, including necrosis and apoptosis, is a hallmark of CNS diseases. Apoptosis leads to further neurological damage and loss of function during secondary SCl. Inhibition of neuronal apoptosis plays a crucial role in functional and pathological recovery following SCl [42]. Apoptosis is a type of programmed cell death regulated by signal transduction pathways. $\mathrm{Bcl}-2$-family proteins are important regulators of apoptosis and include anti-apoptotic proteins (e.g., Bcl-2) and proapoptotic proteins (e.g.,, Bax). A higher Bax/Bcl-2 ratio can form ion channels causing the release of cytochrome $c$ from mitochondria into the cytosol, leading to activation of caspases -9 and -3 , inducing apoptosis [43]. Bax, cleaved caspase -9 , and cleaved caspase -3 were upregulated, and $\mathrm{Bcl}-2$ was downregulated, in the $\mathrm{SCl}$ group, implying that $\mathrm{SCl}$ induces apoptosis. However, RA inhibited activation of cleaved caspase -9 and cleaved caspase -3 and reduced the $\mathrm{Bax} / \mathrm{Bcl}-2$ ratio, indicating inhibition of apoptosis. Furthermore, the number of TUNEL-positive cells was decreased by RA, also implying inhibition of apoptosis.

SCl-induced apoptosis and mitochondrial dysfunction lead to ROS and lipid peroxide accumulation, which is implicated in the deterioration of $\mathrm{SCl}$ [44]. The abundance of lipids in spinal cord tissue means that it is easily injured by lipid peroxidation and ROS. SOD catalyzes the disproportionation of superoxide anion and is the main antioxidant enzyme that scavenges ROS, protecting against ROS-induced damage [24]. CAT decomposes 
$\mathrm{H}_{2} \mathrm{O}_{2}$ into $\mathrm{H}_{2} \mathrm{O}$ and $\mathrm{O}_{2}$ and protects cells from $\mathrm{H}_{2} \mathrm{O}_{2}$-induced damage [45]. GSH-Px removes $\mathrm{H}_{2} \mathrm{O}_{2}$ and lipid peroxides, protecting the cell membrane [23]. MDA is the final product of polyunsaturated fatty acids, and its content is an important indicator of lipid peroxidation [24]. Therefore, SOD, CAT, and GSH-Px activity and the MDA content can be measured as indicators of oxidative stress damage secondary to SCl. Our results indicate that RA attenuated the increased MDA content and SOD, CAT, and GSH-Px activities, protecting SCI rats from oxidative injury and overproduction of ROS.

Excessive inflammation is also implicated in the pathogenesis of SCl by contributing to neuronal apoptosis and multiple secondary injuries [6]. Microglia are unique to the CNS. After trauma or infection, expression of CD11b is increased in microglia, triggering secretion of IL-10, TNF-a, IL-6, IL-1 $\beta$, and ROS [46]. In SCI, activated microglia secrete proinflammatory cytokines, induce astrocyte activation, promote glial scar formation, destroy the oligodendrocytes that are responsible for myelination of multiple axons, and induce axonal death [47]. Thus, the microglia-mediated inflammatory response plays an important role in secondary injury after $\mathrm{SCl}$, and blocking the activation of microglia and the production of proinflammatory mediators may have therapeutic potential for SCI. RA attenuated microglia activation and TNF-a, IL-6, and IL-1 $\beta$ secretion, and promoted release of IL-10 in the injured spinal cord, so the amelioration by RA of SCl may be related to microglia inhibition and its anti-inflammatory activity.

To verify the molecular mechanisms of the anti-apoptotic, antioxidant, and anti-inflammatory activities of RA, we performed a proteomics analysis of the spinal cord tissue of SCI and RA-treated SCI rats; this resulted in identification of 16 protein spots. Among them, 10 proteins (Gal-1, UCHL1, PRDX6, FABP2, TF, HO-1, HSPA1A, NEFL, NEFM, and ARG1) were upregulated, and 6 (PMP22, ANXA2, AKR1B1, CTSB, HSP27, and PRDX1) were downregulated. Western blotting confirmed these results. The levels of HO-1, HSP90, HSP27, ANXA2, AKR1B1, and ARG1, which are associated with the Nrf2 and NF-KB signaling pathways, were markedly changed. HO-1 is an important antioxidant enzyme of the downstream Nrf2 signaling pathway [23, 24]. Inhibition of HSP90 prevents atherosclerosis in experimental diabetes by inducing Nrf2-dependent cytoprotective mechanisms [48]. Salari et al. reported that treatment of human macrophages with recombinant HSP27 induced degradation of IKBa, nuclear translocation of the NF-KB p65 subunit, and activation of downstream NF-KB transcriptional activity [49]. In addition, ANXA2 induced activation of NF-KB through TLR4, resulting in proinflammatory cytokine production [50]. AKR1B1 is upregulated in SCl rats, interacts with the NF-KB pathway and promotes astrocyte proliferation and an inflammatory response [51]. ARG1, as a marker of anti-inflammatory M2 microglia, is associated with induction of NF-KB via TLR4 [52].

Next, we performed a bioinformatics analysis (protein network, GO, and pathway analyses) of the 16 proteins. STRING analyses revealed that the proteins were closely clustered in an interaction network centered on $\mathrm{HO}-1$, HSP90, HSP27, and ANXA2. Also, 17 GO functions were annotated as MF, 287 as BP, and 69 as CC. In addition, a reactome pathway analysis showed that the proteins were enriched in the neutrophil degranulation, detoxification of ROS, iron uptake and transport, cellular responses to stress, post-translational protein phosphorylation, and regulation of the IGF transport pathway. Therefore, the neuroprotective effect of RA on $\mathrm{SCl}$ may be mediated by improved energy metabolism and prevention of oxidative stress and inflammation.

Nrf2 interacts with antioxidant response elements, followed by activation of downstream antioxidant proteins [19]. Also, Nrf2 regulates the expression of a panel of antioxidants and detoxification enzymes and plays an 
important role in regulating oxidative stress and inflammation. Especially in CNS diseases, Nrf2 plays a key role in defending against potential oxidative stress or insults [53]. Therefore, modulating Nrf2 may prevent oxidative-stress-induced injury in CNS diseases. Nrf2 activators exert a neuroprotective effect in animal models of SCl. Zhang et al. found that sinomenine attenuated traumatic SCl by inhibiting oxidative stress and inflammation by activating the Nrf2 pathway [24]. Normally, the binding of Nrf2 to Keap1 in the cytoplasm prevents its nuclear translocation. Stimulation by physicochemical factors disrupts this binding to Keap1, leading to nuclear translocation of Nrf2, whereby it binds to antioxidant response elements and activates transcription of genes encoding detoxification enzymes and cytoprotective proteins, such as NQO1, SOD, and HO- 1 [21, 22]. HO- 1 prevents oxidative stress, inflammation and metabolic disorders [23, 24]. RA promotes nuclear translocation of Nrf2 and increases $\mathrm{HO}-1$ levels. Similarly, the antioxidant and anti-apoptotic activities of RA reportedly protect against ischemic stroke by upregulating Nrf2 and HO-1 expression [54].

NF-KB is a central transcription factor in the inflammatory response and regulates cell proliferation and apoptosis [29]. Inactive NF-KB exists in the cytoplasm in the form of a trimer that aggregates with IKB. Upon stimulation by bacterial or viral infection, inflammatory factors, or LPS, activation of inhibitor of NF-KB kinase (IKK) triggers dissociation of the cytoplasmic NF-B/IB complex. The IKK-mediated phosphorylation and proteasomal degradation of IB facilitates the nuclear translocation of active NF-B transcription factor subunit (p65), causing release of IL-6, IL-1 $\beta$, and TNF-a $[55,56]$. In addition, the Toll-like receptor 4 (TLR4)-mediated myeloid differentiation factor-88 (MyD88) signaling pathway plays an important role in regulating the inflammatory response [57]. TLR4 is activated by LPS, resulting in the recruitment and activation of the signal adaptor MyD88 by the interaction between the intracellular TH domain of TLR4 and the carboxy-terminal TH domain of MyD88. The activation of MyD88 triggers activation of the NF-KB signaling pathway and the production of proinflammatory cytokines [58]. We found that the anti-inflammatory effect of RA on SCI was due to downregulation of TLR4, MyD88, p-IKKa/ $\beta, \mathrm{p}-\mathrm{IBa}$, and p65 (nucleus), and upregulation of p65 (cytoplasm). Similarly, RA reportedly mitigated the LPS-induced neuroinflammatory response by inhibiting TLR4/NF-KB-mediated inflammasome activation [59].

In support of the above, RA prevented $\mathrm{H}_{2} \mathrm{O}_{2}$-induced cytotoxicity, oxidative damage, and apoptosis, and activation of the Nrf2/HO-1 pathway in PC12 cells. Also, RA protected PC12 cells from LPS-induced cytotoxicity, inflammatory damage, and apoptosis, and inactivated the TLR4//NF-KB pathway.

To investigate whether the effect of RA on SCl was dependent on the presence of Nrf2, we used a Nrf2 inhibitor (ML385). The Nrf2 level in spinal cord tissue was significantly decreased by ML385. Also, ML385 reversed RAinduced functional recovery and inhibition of apoptosis in $\mathrm{SCl}$ rats. This was confirmed by the contents of SOD, CAT, GSH-Px, and MDA and the levels of TNF-a, IL-6, IL-1 $\beta$, and IL-10. Also, the inhibition of Nrf2 reversed the RA-mediated antioxidant and anti-inflammatory effects. Nrf2 has been reported to exert an antiinflammatory effect and to suppress activation of NF-KB [27]. HO-1 is regulated by Nrf2, and limits NF-KB activity by suppressing IKB degradation [60]. Activators of Nrf2, such as phenethyl isothiocyanate (PEITC) and curcumin (CUR), attenuate IKK/IKB phosphorylation and NF-B p65 nuclear translocation, inhibiting the NF-KB signaling pathway [61]. We found that blockade of Nrf2 by ML385 reversed the RA-induced downregulation of $\mathrm{p}-\mathrm{IKKa} / \beta, \mathrm{p}-\mathrm{IBa}$, and p65 (nucleus) and upregulation of p65 (cytoplasm). Therefore, RA inhibits the NF-KB signaling pathway indirectly by activating the Nrf2 signaling pathway.

Page $15 / 36$ 
There is reportedly strong crosstalk between the Nrf2 and NF-KB signaling pathways [60, 61]. NF-kB inhibits Nrf2 signaling at the transcriptional level. NF-KB competitively removes Nrf2 from CREB-binding protein, causing its inactivation; NF-KB recruits histone deacetylase 3 , causing local hypoacetylation and blocking the Nrf2 signaling pathway [62]. NF-KB inhibitors, such as pyrrolidine dithiocarbamate and MG132, increase the HO-1 mRNA and protein levels [63]. Thus, whether RA activates the Nrf2 signaling pathway indirectly by inhibiting NF-KB warrants further investigation.

\section{Conclusion}

In conclusion, RA exerted a neuroprotective effect in vivo and in vitro by inhibiting oxidative stress, inflammation, and apoptosis via the Nrf2, NF-KB, and caspase-3 pathways, respectively. Also, RA activated the $\mathrm{Nrf} 2 / \mathrm{HO}-1$ signaling pathway and inhibited the TLR4/NF-KB signaling pathway. Finally, RA improved the locomotor function of $\mathrm{SCl}$ rats, implying its potential as a target for the development of therapeutics for $\mathrm{SCl}$.

\section{Abbreviations}

SCl: spinal cord injury; RA: rosmarinic acid; TNF-a: tumor necrosis factor-a; IL-6: interleukin-6; IL-1ß: interleukin-1 $\beta$; IL-10: interleukin-10; MDA: malondialdehyde; SOD: superoxide dismutase; CAT: catalase; GSH-Px: glutathione peroxidase; LDH: lactate dehydrogenase; CNS: central nervous system; ROS: reactive oxygen species; Nrf2: nuclear factor erythroid-derived 2-related factor 2; Keap1: kelch-like ECH-associated protein 1; ARE: anti-oxidant responsive element; $\mathrm{HO}-1$ : heme oxygenase-1; NQ01: NAD(P)H quinoneoxidoreductase 1; NF-KB: nuclear factor kappa beta; 2-DE: two-dimensional electrophoresis; BBB: Basso, Beattie, and Bresnahan; PFA: paraformaldehyde; SDS: sodium dodecyl sulfate; IKK: inhibitor of NF-KB kinase; TLR4: toll like receptor 4; MyD88: myloid differentiation factor-88; PEITC: phenethyl isothiocyanate; CUR: curcumin; CBP: CREB-binding protein; HDAC3: histone deacetylase 3; PDTC: pyrrolidine dithiocarbamate.

\section{Declarations}

\section{Acknowledgments}

We are grateful for the supported by the international cooperation base of Gansu province for the pain research in spinal disorders and institute of Integrated Traditional Chinese and Western Medicine of Lanzhou University, Lanzhou, China.

\section{Author contributions}

$X W K$ and YGW conceived and designed the study. XWK guided the project. ZJM and YBL coordinated and performed most experimental work. FGY, XGH, and EHR performed statistical analyses. YCG and GZZ contributed reagents/materials/analysis tools. ZJM and SPL wrote the manuscript, and XWK provided critical review.

\section{Founding}


This work was financially supported by the Chinese Medicine Administration Research Project of Gansu province (GZK-2019-46) and Cuiying Scientific Training Program for Undergraduates of Lanzhou University Second Hospital (CYXZ-11; CYXZ-09) and Doctoral Research Fund of Lanzhou University Second Hospital (ynbskyjj2015-2-10).

\section{Availability of data and materials}

All data generated or analyzed during this study are available on request.

\section{Ethics approval and consent to participate}

All animal procedures were conducted in strict accordance with the institutional ethics committee of Lanzhou University.

\section{Consent for publication}

Not applicable.

\section{Competing interests}

The authors declare that they have no competing interests.

\section{Author details}

${ }^{1}$ The Second Clinical Medical College, Lanzhou University, Lanzhou, Gansu 730030, China. ${ }^{2}$ Department of Orthopedics, Lanzhou University Second Hospital, Lanzhou, Gansu 730030, China.

${ }^{3}$ The international cooperation base of Gansu province for the pain research in spinal disorders, Gansu 730000, China.

\section{References}

[1] Fakhoury M. Spinal cord injury: overview of experimental approaches used to restore locomotor activity. Rev Neurosci. 2015; 26: 397-405.

[2] Choo AM, Liu J, Dvorak M, Tetzlaff W, Oxland TR. Secondary pathology following contusion, dislocation, and distraction spinal cord injuries. Exp Neurol. 2008; 212: 490-506.

[3] Özdemir ÜS, Nazıroğlu M, Şenol N, Ghazizadeh V. Hypericum perforatum Attenuates Spinal Cord InjuryInduced Oxidative Stress and Apoptosis in the Dorsal Root Ganglion of Rats: Involvement of TRPM2 and TRPV1 Channels. Mol Neurobiol. 2016; 53: 3540-3551.

[4] Silva NA, Sousa N, Reis RL, Salgado AJ. From basics to clinical: a comprehensive review on spinal cord injury. Prog Neurobiol. 2014; 114: 25-57.

[5] Chen X, Chen X, Huang X, Qin C, Fang Y, Liu Y, Zhang G, Pan D, Wang W, Xie M. Soluble epoxide hydrolase inhibition provides multi-target therapeutic effects in rats after spinal cord injury. Mol Neurobiol. 2016; 53: 
$1565-1578$.

[6] Anwar MA, Al Shehabi TS, Eid AH. Inflammogenesis of Secondary Spinal Cord Injury. Front Cell Neurosci. 2016; 10: 98.

[7] Zhang MM, Qiao Y, Ang EL, Zhao H. Using natural products for drug discovery: the impact of the genomics era. Expert Opin Drug Discov. 2017; 12: 475-487.

[8] Kuźniak E, Kornas A, Kaźmierczak A, Rozpądek P, Nosek M, Kocurek M, Zellnig G, Müller M, Miszalski Z. Photosynthesis-related characteristics of the midrib and the interveinal lamina in leaves of the C3-CAM intermediate plant Mesembryanthemum crystallinum. Ann Bot. 2016; 117: 1141-1151.

[9] Zhang Q, Yang H, An J, Zhang R, Chen B, Hao D. Therapeutic Effects of Traditional Chinese Medicine on Spinal Cord Injury: A Promising Supplementary Treatment in Future. Evid Based Complement Alternat Med. 2016; 2016: 8958721.

[10] al-Sereiti MR, Abu-Amer KM, Sen P. Pharmacology of rosemary (Rosmarinus officinalis Linn.) and its therapeutic potentials. Indian J Exp Biol. 1999; 37: 124-130.

[11] Boonyarikpunchai W, Sukrong S, Towiwat P. Antinociceptive and anti-inflammatory effects of rosmarinic acid isolated from Thunbergia laurifolia Lindl. Pharmacol Biochem Behav. 2014; 124: 67-73.

[12] Nabavi SF, Tenore GC, Daglia M, Tundis R, Loizzo MR, Nabavi SM. The cellular protective effects of rosmarinic acid: from bench to bedside. Curr Neurovasc Res. 2015; 12: 98-105.

[13] Rahbardar MG, Amin B, Mehri S, Mirnajafi-Zadeh SJ, Hosseinzadeh H. Rosmarinic acid attenuates development and existing pain in a rat model of neuropathic pain: An evidence of anti-oxidative and antiinflammatory effects. Phytomedicine. 2018; 40: 59-67.

[14] Bigford GE, Del Rossi G. Supplemental substances derived from foods as adjunctive therapeutic agents for treatment of neurodegenerative diseases and disorders. Adv Nutr. 2014; 5: 394-403.

[15] Zhang M, Yan H1, Li S, Yang J. Rosmarinic acid protects rat hippocampal neurons from cerebral ischemia/reperfusion injury via the Akt/JNK3/caspase-3 signaling pathway. Brain Res. 2017; 1657: 9-15.

[16] Cui HY, Zhang XJ, Yang Y, Zhang C, Zhu CH, Miao JY, Chen R. Rosmarinic acid elicits neuroprotection in ischemic stroke via Nrf2 and heme oxygenase 1 signaling. Neural Regen Res. 2018; 13: 2119-2128.

[17] Ghaffari H, Venkataramana M, Jalali Ghassam B, Chandra Nayaka S, Nataraju A, Geetha NP, Prakash HS. Rosmarinic acid mediated neuroprotective effects against $\mathrm{H} 2 \mathrm{O} 2$-induced neuronal cell damage in N2A cells. Life Sci. 2014; 113: 7-13.

[18] Shang AJ, Yang Y, Wang HY, Tao BZ, Wang J, Wang ZF, Zhou DB. Spinal cord injury effectively ameliorated by neuroprotective effects of rosmarinic acid. Nutr Neurosci. 2017; 20: 172-179.

[19] Kobayashi M, Yamamoto M. Molecular mechanisms activating the Nrf2-Keap1 pathway of antioxidant gene regulation. Antioxid Redox Signal. 2005; 7: 385-394. 
[20] O'Connell MA, Hayes JD. The Keap1/Nrf2 pathway in health and disease: from the bench to the clinic. Biochem Soc Trans. 2015; 43: 687-689.

[21] Dwivedi S, Rajasekar N, Hanif K, Nath C, Shukla R. Sulforaphane Ameliorates Okadaic Acid-Induced Memory Impairment in Rats by Activating the Nrf2/HO-1 Antioxidant Pathway. Mol Neurobiol. 2016; 53: 5310-5323.

[22] Zhai X, Chen X, Shi J, Shi D, Ye Z, Liu W, Li M, Wang Q, Kang Z, Bi H, Sun X. Lactulose ameliorates cerebral ischemia-reperfusion injury in rats by inducing hydrogen by activating Nrf2 expression. Free Radic Biol Med. 2013; 65: 731-741.

[23] Wang L, Yao Y, He R, Meng Y, Li N, Zhang D, Xu J, Chen O, Cui J, Bian J, Zhang Y, Chen G, Deng X. Methane ameliorates spinal cord ischemia-reperfusion injury in rats: Antioxidant, anti-inflammatory and anti-apoptotic activity mediated by Nrf2 activation. Free Radic Biol Med. 2017; 103: 69-86.

[24] Zhang L, Zhang W, Zheng B, Tian N. Sinomenine Attenuates Traumatic Spinal Cord Injury by Suppressing Oxidative Stress and Inflammation via Nrf2 Pathway. Neurochem Res. 2019; 44: 763-775.

[25] Morito N, Yoh K, Hirayama A, Itoh K, Nose M, Koyama A, Yamamoto M, Takahashi S. Nrf2 deficiency improves autoimmune nephritis caused by the fas mutation Ipr. Kidney Int. 2004; 65: 1703-1713.

[26] Qin T, Du R, Huang F, Yin S, Yang J, Qin S, Cao W. Sinomenine activation of Nrf2 signaling prevents hyperactive inflammation and kidney injury in a mouse model of obstructive nephropathy. Free Radic Biol Med. 2016; 92: 90-99.

[27] Bao L, Li J, Zha D, Zhang L, Gao P, Yao T, Wu X. Chlorogenic acid prevents diabetic nephropathy by inhibiting oxidative stress and inflammation through modulation of the Nrf2/HO-1 and NF-KB pathways. Int Immunopharmacol. 2018; 54: 245-253.

[28] Li Q, Verma IM. NF-kappaB regulation in the immune system. Nat Rev Immunol. 2002; 2: 725-734.

[29] Liu G, Fan G, Guo G, Kang W, Wang D, Xu B, Zhao J. FK506 Attenuates the Inflammation in Rat Spinal Cord Injury by Inhibiting the Activation of NF-KB in Microglia Cells. Cell Mol Neurobiol. 2017; 37: 843-855.

[30] Basso DM, Beattie MS, Bresnahan JC. A sensitive and reliable locomotor rating scale for open field testing in rats. J Neurotrauma. 1995; 12: 1-21.

[31] Perrin FE, Boniface G, Serguera C, Lonjon N, Serre A, Prieto M, Mallet J, Privat A. Grafted human embryonic progenitors expressing neurogenin-2 stimulate axonal sprouting and improve motor recovery after severe spinal cord injury. PLoS One. 2010; 5: e15914.

[32] Lu L, Chen G, Yang J, Ma Z, Yang Y, Hu Y, Lu Y, Cao Z, Wang Y, Wang X. Bone marrow mesenchymal stem cells suppress growth and promote the apoptosis of glioma U251 cells through downregulation of the PI3K/AKT signaling pathway. Biomed Pharmacother. 2019; 112: 108625. 
[33] Ma ZJ, Wang XX, Su G, Yang JJ, Zhu YJ, Wu YW, Li J, Lu L, Zeng L, Pei HX. Proteomic analysis of apoptosis induction by lariciresinol in human HepG2 cells. Chem Biol Interact. 2016; 256: 209-219.

[34] Tian R, Shi R. Dimercaprol is an acrolein scavenger that mitigates acrolein-mediated PC-12 cells toxicity and reduces acrolein in rat following spinal cord injury. J Neurochem. 2017; 141: 708-720.

[35] Li R, Yin F, Guo YY, Zhao KC, Ruan Q, Qi YM. Knockdown of ANRIL aggravates H2O2-induced injury in PC12 cells by targeting microRNA-125a. Biomed Pharmacother. 2017; 92: 952-961.

[36] Kumar H, Ropper AE, Lee SH, Han I. Propitious Therapeutic Modulators to Prevent Blood-Spinal Cord Barrier Disruption in Spinal Cord Injury. Mol Neurobiol. 2017; 54: 3578-3590.

[37] Thompson CD, Zurko JC, Hanna BF, Hellenbrand DJ, Hanna A. The therapeutic role of interleukin-10 after spinal cord injury. J Neurotrauma. 2013; 30: 1311-1324.

[38] Nestler EJ, Barrot M, DiLeone RJ, Eisch AJ, Gold SJ, Monteggia LM. Neurobiology of depression. Neuron. 2002; 34: 13-25.

[39] Yin F, Guo L, Meng CY, Liu YJ, Lu RF, Li P, Zhou YB. Transplantation of mesenchymal stem cells exerts antiapoptotic effects in adult rats after spinal cord ischemia-reperfusion injury. Brain Res. 2014; 1561: 1-10.

[40] Argaw AT, Asp L, Zhang J, Navrazhina K, Pham T, Mariani JN, Mahase S, Dutta DJ, Seto J, Kramer EG, Ferrara N, Sofroniew MV, John GR. Astrocyte-derived VEGF-A drives blood-brain barrier disruption in CNS inflammatory disease. J Clin Invest. 2012; 122: 2454-2468.

[41] Orlandin JR, Ambrósio CE, Lara VM. Glial scar-modulation as therapeutic tool in spinal cord injury in animal models. Acta Cir Bras. 2017; 32: 168-174.

[42] Li Y, Guo Y, Fan Y, Tian H, Li K, Mei X. Melatonin Enhances Autophagy and Reduces Apoptosis to Promote Locomotor Recovery in Spinal Cord Injury via the PI3K/AKT/mTOR Signaling Pathway. Neurochem Res. 2019; 44: 2007-2019.

[43] Lin W, Xie J, Xu N, Huang L, Xu A, Li H, Li C, Gao Y, Watanabe M, Liu C, Huang P. Glaucocalyxin A induces G2/M cell cycle arrest and apoptosis through the PI3K/Akt pathway in human bladder cancer cells. Int J Biol Sci. 2018; 14: 418-426.

[44] Pei JP, Fan LH, Nan K, Li J, Dang XQ, Wang KZ. HSYA alleviates secondary neuronal death through attenuating oxidative stress, inflammatory response, and neural apoptosis in SD rat spinal cord compression injury. J Neuroinflammation. 2017; 14(1): 97.

[45] Francos-Quijorna I, Santos-Nogueira E, Gronert K, Sullivan AB, Kopp MA, Brommer B, David S, Schwab JM, López-Vales R. Maresin 1 Promotes Inflammatory Resolution, Neuroprotection, and Functional Neurological Recovery After Spinal Cord Injury. J Neurosci. 2017; 37: 11731-11743.

[46] Gensel JC, Zhang B. Macrophage activation and its role in repair and pathology after spinal cord injury. Brain Res. 2015; 1619: 1-11. 
[47] Li X, Chen S, Mao L, Li D, Xu C, Tian H, Mei X. Zinc Improves Functional Recovery by Regulating the Secretion of Granulocyte Colony Stimulating Factor From Microglia/Macrophages After Spinal Cord Injury. Front Mol Neurosci. 2019; 12: 18.

[48] Lazaro I, Oguiza A, Recio C, Lopez-Sanz L, Bernal S, Egido J, Gomez-Guerrero C. Interplay between HSP90 and Nrf2 pathways in diabetes-associated atherosclerosis. Clin Investig Arterioscler. 2017; 29: 51-59.

[49] Salari S, Seibert T, Chen YX, Hu T, Shi C, Zhao X, Cuerrier CM, Raizman JE, O’Brien ER. Extracellular HSP27 acts as a signaling molecule to activate NF-KB in macrophages. Cell Stress Chaperones. 2013; 18: 53-63.

[50] Lei Y, Wang K, Li X, Li Y, Feng X, Zhou J, Zhang Z, Huang C, Zhang T. Cell-surface Translocation of Annexin A2 contributes to bleomycin-induced pulmonary fibrosis by mediating inflammatory response in mice. Clin Sci (Lond). 2019; pii: CS20180687. doi: 10.1042/CS20180687.

[51] Chen X, Chen C, Hao J, Qin R, Qian B, Yang K, Zhang J, Zhang F. AKR1B1 Upregulation Contributes to Neuroinflammation and Astrocytes Proliferation by Regulating the Energy Metabolism in Rat Spinal Cord Injury. Neurochem Res. 2018; 43: 1491-1499.

[52] Zhang F, Zhong R, Li S, Fu Z, Cheng C, Cai H, Le W. Acute Hypoxia Induced an Imbalanced M1/M2 Activation of Microglia through NF-KB Signaling in Alzheimer's Disease Mice and Wild-Type Littermates. Front Aging Neurosci. 2017; 9: 282.

[53] Sun Y, Yang T, Leak RK, Chen J, Zhang F. Preventive and Protective Roles of Dietary Nrf2 Activators Against Central Nervous System Diseases. CNS Neurol Disord Drug Targets. 2017; 16: 326-338.

[54] Cui HY, Zhang XJ, Yang Y, Zhang C, Zhu CH, Miao JY, Chen R. Rosmarinic acid elicits neuroprotection in ischemic stroke via Nrf2 and heme oxygenase 1 signaling. Neural Regen Res. 2018; 13: 2119-2128.

[55] Zhang Q, Lenardo MJ, Baltimore. 30 Years of NF-kB: A Blossoming of Relevance to Human Pathobiology. Cell. 2017; 168: 37-57.

[56] Mao J, Yi M, Wang R, Huang Y, Chen M. Protective Effects of Costunolide Against D-Galactosamine and Lipopolysaccharide-Induced Acute Liver Injury in Mice. Front Pharmacol. 2018; 9: 1469.

[57] Xu MJ, Zhou Z, Parker R, Gao B. Targeting inflammation for the treatment of alcoholic liver disease. Pharmacol Ther. 2017; 180: 77-89.

[58] Kang HH, Kim IK, Lee HI, Joo H, Lim JU, Lee J, Lee SH, Moon HS. Chronic intermittent hypoxia induces liver fibrosis in mice with diet-induced obesity via TLR4/MyD88/MAPK/NF-kB signaling pathways. Biochem Biophys Res Commun. 2017; 490: 349-355.

[59] Wei Y, Chen J, Hu Y, Lu W, Zhang X, Wang R, Chu K. Rosmarinic Acid Mitigates Lipopolysaccharide-Induced Neuroinflammatory Responses through the Inhibition of TLR4 and CD14 Expression and NF-KB and NLRP3 Inflammasome Activation. Inflammation. 2018; 41: 732-740. 
[60] Soares MP, Seldon MP, Gregoire IP, Vassilevskaia T, Berberat PO, Yu J, Tsui TY, Bach FH. Heme oxygenase1 modulates the expression of adhesion molecules associated with endothelial cell activation. $\mathrm{J}$ Immunol. 2004; 172: 3553-3563.

[61] Jeong WS, Kim IW, Hu R, Kong AN. Modulatory properties of various natural chemopreventive agents on the activation of NF-kappaB signaling pathway. Pharm Res. 2004; 21: 661-670.

[62] Liu GH, Qu J, Shen X. NF-kappaB/p65 antagonizes Nrf2-ARE pathway by depriving CBP from Nrf2 and facilitating recruitment of HDAC3 to MafK. Biochim Biophys Acta. 2008; 1783: 713-727.

[63] Min KJ, Lee JT, Joe EH, Kwon TK. An IKBa phosphorylation inhibitor induces heme oxygenase-1(HO-1) expression through the activation of reactive oxygen species (ROS)-Nrf2-ARE signaling and ROS-PI3K/Akt signaling in an NF-KB-independent mechanism. Cell Signal. 2011; 23: 1505-1513.

\section{Tables}

Table 1 Primer sequences for qRT-PCR

\begin{tabular}{cll}
\hline Gene & \multicolumn{1}{c}{ Forward primer sequence } & \multicolumn{1}{c}{ Reverse primer sequence } \\
\hline TNF- $\alpha$ & AAATGGGCTCCCTCTATCAGTTC & TCTGCTTG GTGGTTTGCTACGAC \\
IL-10 & CAGTCAGCCAGACCCACAT & GGCAACCCAAGTAACCCT \\
Nrf2 & ATGAGTCGCTTGCCCTGG & CTTGTTTTCCGTATTAAG \\
HO-1 & ATCGTGCTCGCATGAACACT & CCAACACTGCATTTACATGGC \\
GAPDH & GCACCGTCAAGGCTGAGAAC & ATGGTGGTGAAGACGCCAGT \\
\hline
\end{tabular}

Table 2 MALDI-TOF-MS/MS identification results of differentially expressed protein spots 


\begin{tabular}{|c|c|c|c|c|c|c|c|c|}
\hline $\begin{array}{l}\text { Spot } \\
\text { No. }\end{array}$ & Protein name & $\begin{array}{c}\text { Accession } \\
\text { No. }\end{array}$ & $\begin{array}{l}\text { MW } \\
\text { (KD) }\end{array}$ & $\mathrm{pI}$ & score & $\begin{array}{c}\text { Sequence } \\
\text { coverage } ₫ \% \square\end{array}$ & matches & $\begin{array}{c}\text { Expression } \\
\text { change }\end{array}$ \\
\hline 1 & $\begin{array}{c}\text { Peripheral } \\
\text { myelin protein } \\
2\end{array}$ & P25094 & 15.06 & 9.61 & 207 & 25 & $4(4)$ & Decrease \\
\hline 2 & Annexin A2 & Q07936 & 38.68 & 7.5 & 190 & 19 & $4(3)$ & Decrease \\
\hline 3 & Galectin-1 & P11762 & 26.38 & 8.59 & 57 & 14 & $2(2)$ & Increase \\
\hline 4 & $\begin{array}{l}\text { Aldose } \\
\text { reductase }\end{array}$ & P07943 & 36.23 & 6.26 & 64 & 34 & $5(4)$ & Decrease \\
\hline 5 & Cathepsin B & P00787 & 38.43 & 5.47 & 212 & 10 & $2(2)$ & Decrease \\
\hline 6 & $\begin{array}{c}\text { Heat shock } \\
\text { 27kDa protein } \\
1\end{array}$ & P42930 & 22.85 & 5.86 & 192 & 20 & $3(3)$ & Decrease \\
\hline 7 & $\begin{array}{c}\text { Ubiquitin } \\
\text { carboxyl- } \\
\text { terminal } \\
\text { hydrolase } \\
\text { isozyme L1 }\end{array}$ & Q00981 & 25.17 & 5.14 & 556 & 44 & $5(5)$ & Increase \\
\hline 8 & $\begin{array}{c}\text { Peroxiredoxin- } \\
6\end{array}$ & O35244 & 24.86 & 5.64 & 168 & 28 & $4(4)$ & Increase \\
\hline 9 & $\begin{array}{l}\text { Fatty acid- } \\
\text { binding } \\
\text { protein, brain }\end{array}$ & P55051 & 15.14 & 5.46 & 92 & 17 & $2(2)$ & Increase \\
\hline 10 & Serotransferrin & P12346 & 109.51 & 6.40 & 221 & 44 & $4(4)$ & Increase \\
\hline 11 & $\begin{array}{c}\text { Heme } \\
\text { Oxygenase } 1\end{array}$ & P06762 & 32.00 & 4.80 & 249 & 25 & $5(4)$ & Increase \\
\hline 12 & $\begin{array}{l}\text { Heat shock } 70 \\
\text { kDa protein } 1 \mathrm{~A}\end{array}$ & P0DMWO & 69.80 & 5.5 & 82 & 38 & $6(4)$ & Increase \\
\hline 13 & $\begin{array}{c}\text { Peroxiredoxin } \\
1\end{array}$ & Q63716 & 22.11 & 8.27 & 141 & 59 & $5(5)$ & Decrease \\
\hline 14 & $\begin{array}{l}\text { Neurofilament } \\
\text { medium } \\
\text { polypeptide }\end{array}$ & P12839 & 95.90 & 4.77 & 112 & 19 & $2(2)$ & Increase \\
\hline 15 & $\begin{array}{c}\text { Neurofilament } \\
\text { light } \\
\text { polypeptide }\end{array}$ & P19527 & 61.50 & 4.64 & 104 & 31 & $5(5)$ & Increase \\
\hline 16 & Arginase-1 & P07824 & 34.71 & 6.60 & 91 & 46 & $4(3)$ & Increase \\
\hline
\end{tabular}




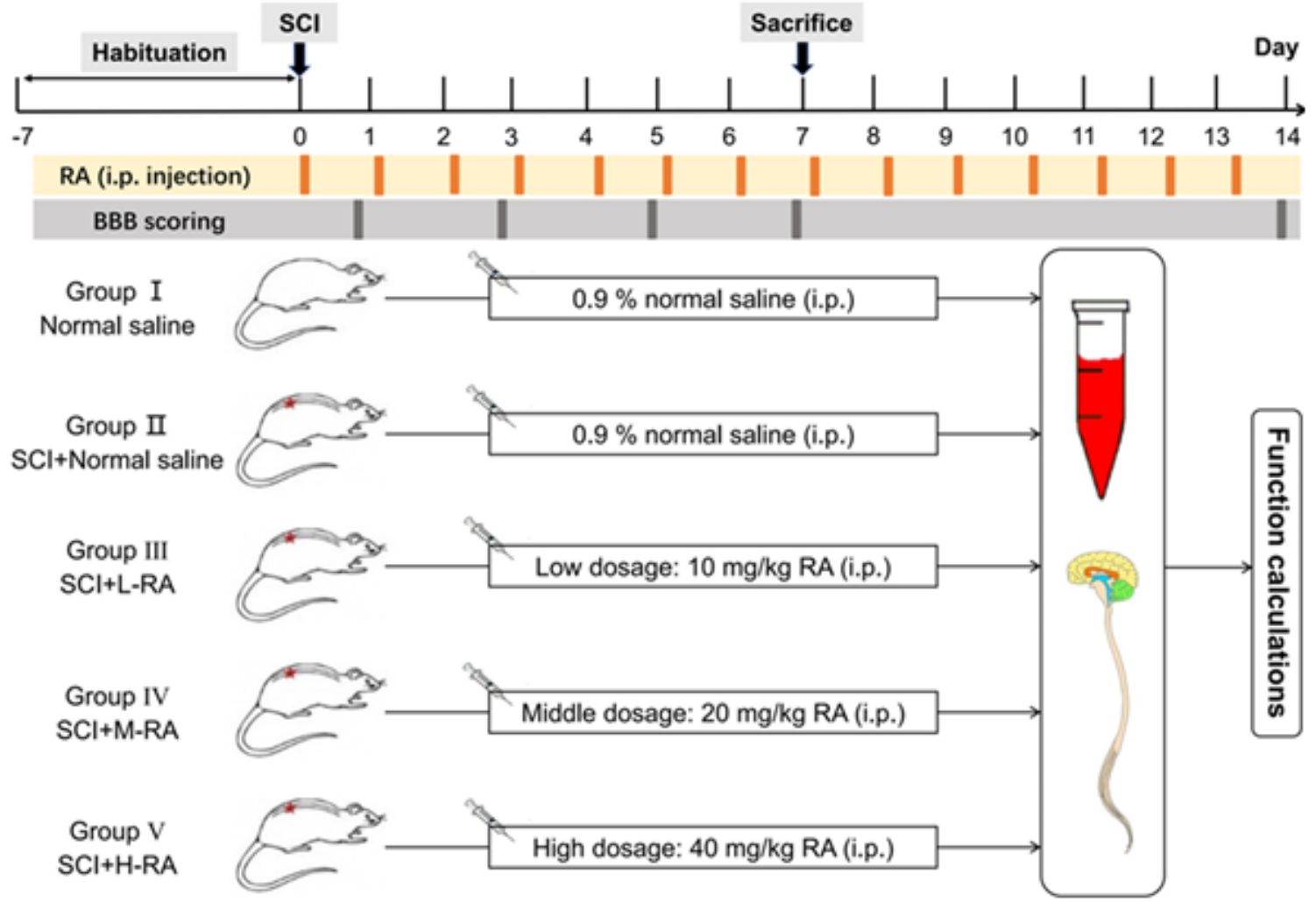

\section{Figure 1}

The diagrammatic of study design in vivo. 


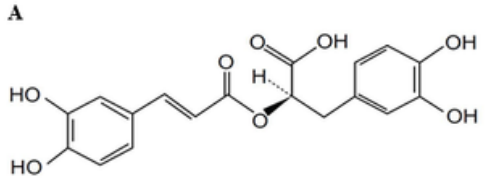

C)
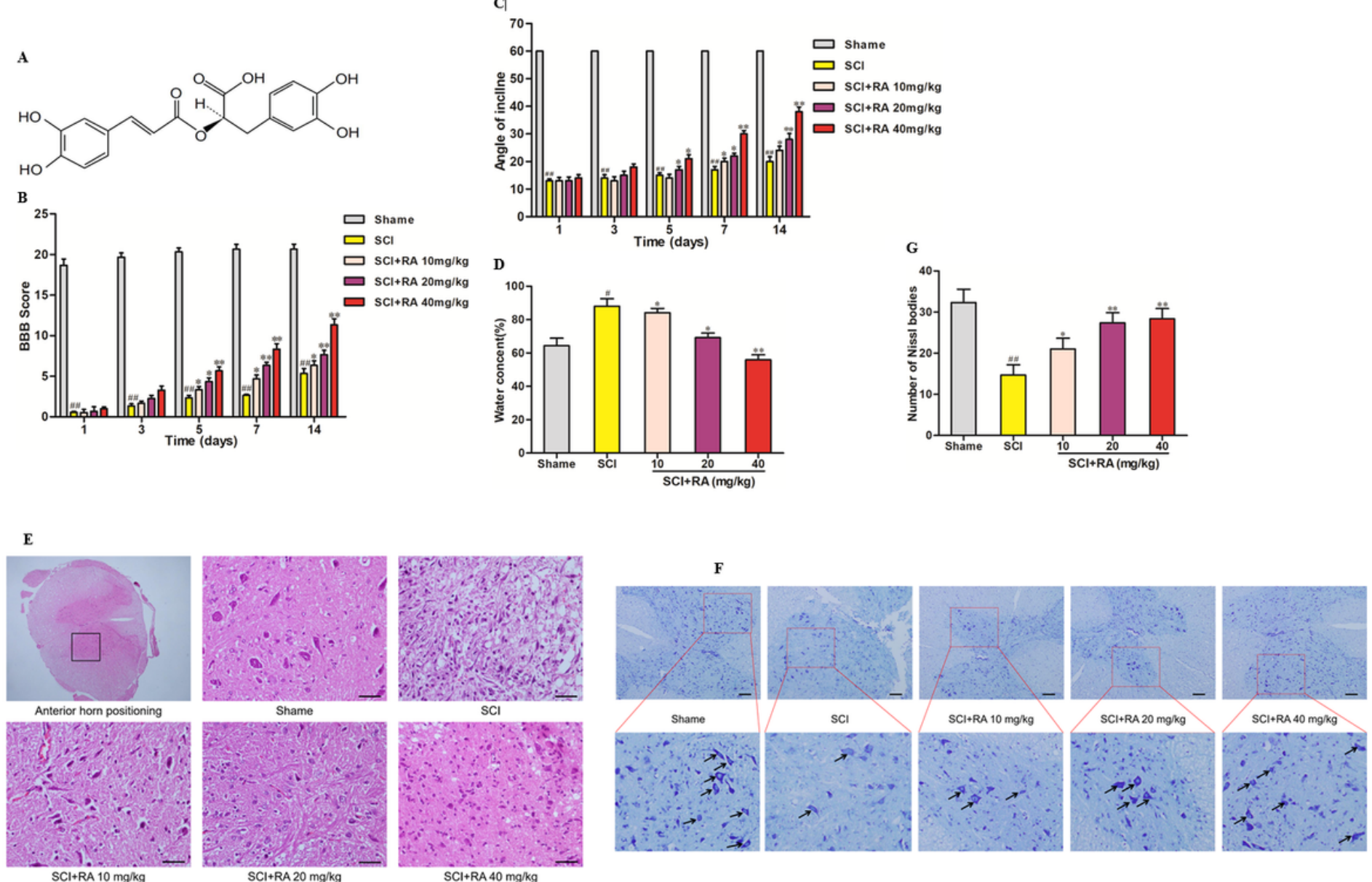

$\mathrm{SCl}+\mathrm{RA} 40 \mathrm{mg} / \mathrm{kg}$

\section{Figure 2}

RA improves the recovery of motor function and tissue repair after SCI. A. Chemical structure of RA. B. BBB scores were calculated to evaluate the hind limb recovery at day 1, 3, 5, 7, and 14 of the sham, $\mathrm{SCl}$ and $\mathrm{SCl}+$ RA group, respectively. C. The inclined plane test scores were performed at day 1, 3, 5, 7, and 14 of different groups. D. Effect of RA on the water content in the injured spinal cord areas in the different groups at 7 days after SCl. E. HE staining results of sections from the anterior horn of injured spinal cord in the different groups at 7 days after $\mathrm{SCl}$ (magnification $\times 400$, scale bar $=50 \mu \mathrm{m}$ ). F. Representative images of Nissl staining of sections from the anterior horn of injured spinal cord in the different groups at 7 days after SCl (scale bar $=50$ $\mu \mathrm{m})$. Enlarged images of boxed areas are shown below. G. Quantification analysis of the number of Nissl staining cells at 7 days after $\mathrm{SCl}$. The results are expressed as means \pm SD from three independent experiments ( $\mathrm{n}=6$ per group). \#p $<0.05$ or \#\#p $<0.01$ vs. Sham group; ${ }^{\star} p<0.05$ or ** $<0.01$ vs. SCl group. 
A

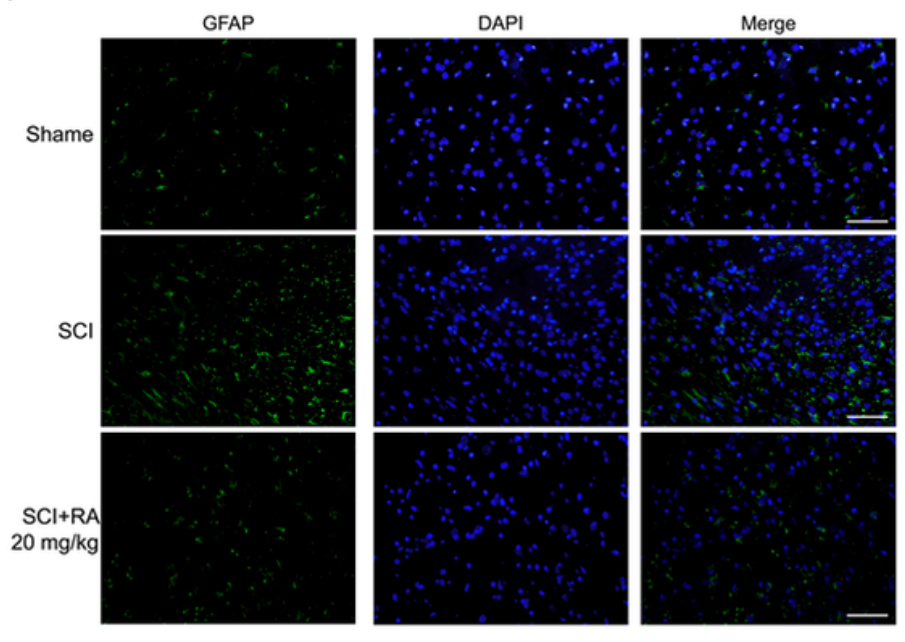

C

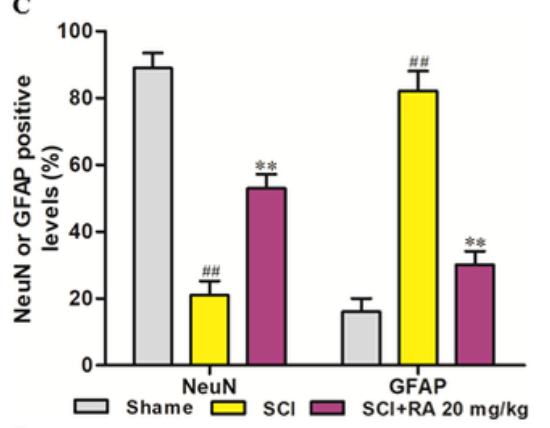

D

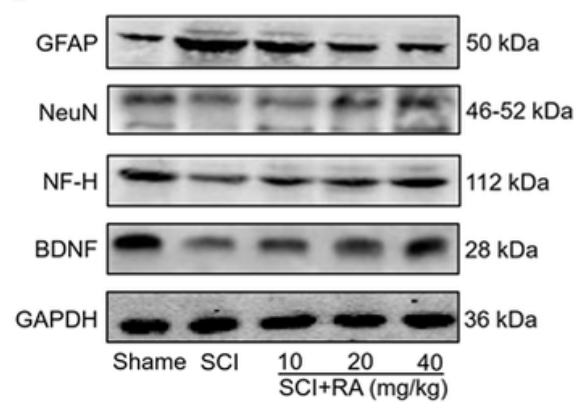

B

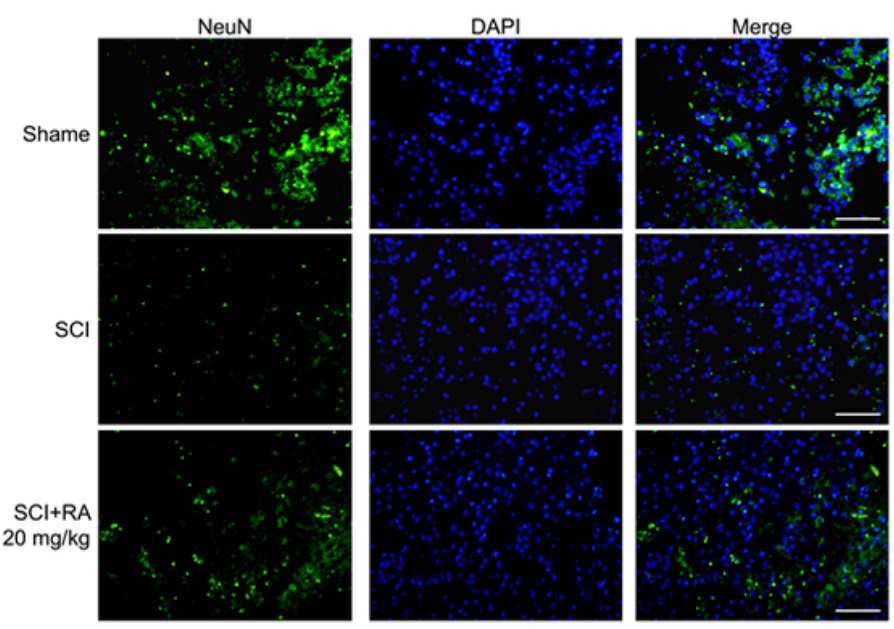

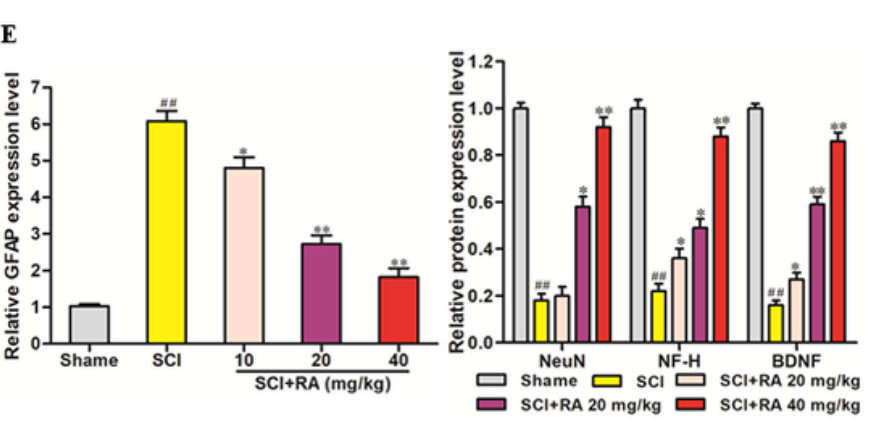

Figure 3

RA improved the txpression of neurotrophins in SCl rats. A, B. Representative immunofluorescence images of GFAP and NeuN of sections from the anterior horn of injured spinal cord in sham, SCl, and SCl+RA group at 7 days after SCI. The nuclei were stained with DAPI (blue) and the images were obtained through fluorescent microscope (magnification $\times 200$, scale bar $=50 \mu \mathrm{m}$ ). C. Quantification of the number of GFAP- and NeuNpositive cells at 7 days after SCI. D, E. Protein expressions and quantification of GFAP, NeuN, NF-H, and BDNF from segments of the injured spinal cord in the different groups at 7 days after SCI. The results are expressed as means \pm SD from three independent experiments ( $n=6$ per group). \#p $<0.05$ or \#\#p $<0.01$ vs. Sham group; ${ }^{*} \mathrm{p}<0.05$ or ${ }^{* *} \mathrm{p}<0.01$ vs. SCl group. 
A

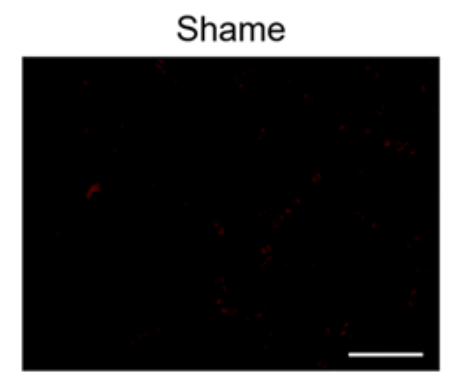

$\mathrm{SCl}+\mathrm{RA} 20 \mathrm{mg} / \mathrm{kg}$

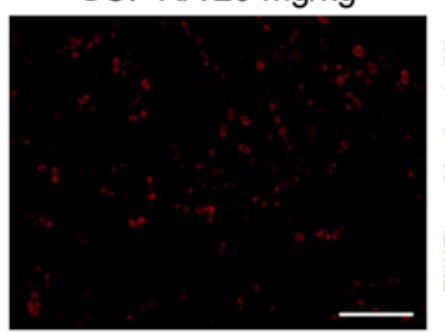

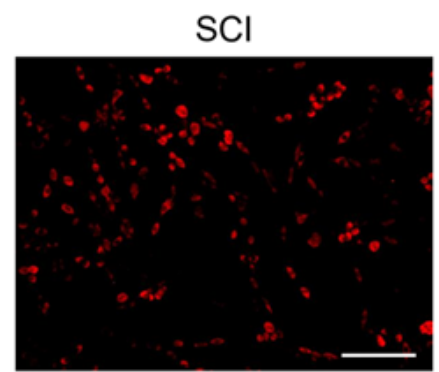

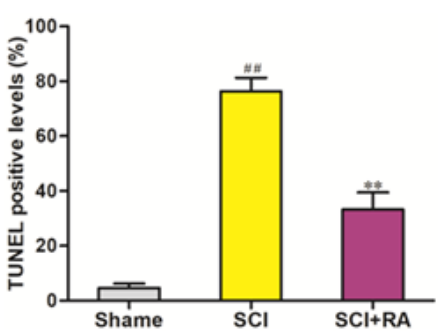

Shame

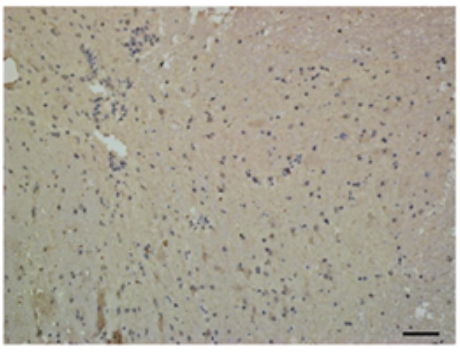

$\mathrm{SCl}+\mathrm{RA} 20 \mathrm{mg} / \mathrm{kg}$

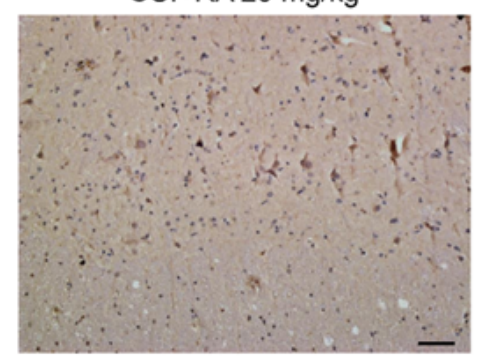

$\mathrm{SCl}$
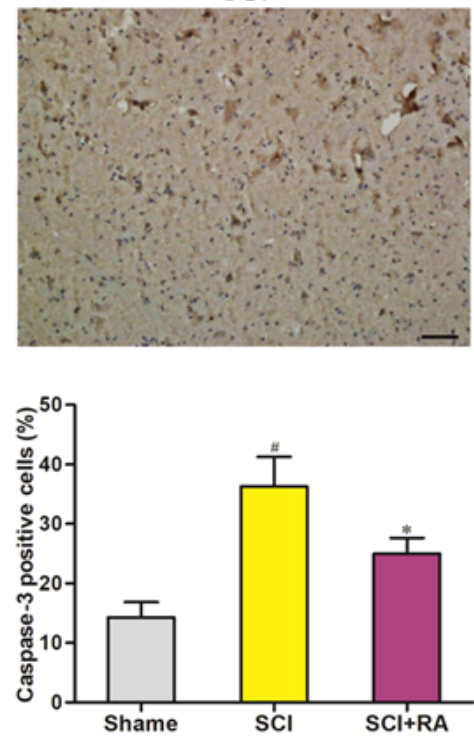

C

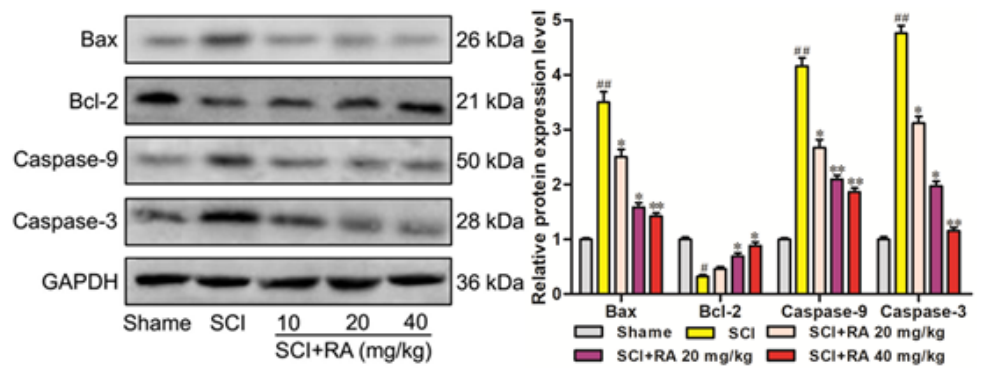

\section{Figure 4}

RA inhibited apoptosis in the spinal cord of SCI rats. A. Representative TUNEL staining images and quantification of sections from the anterior horn of injured spinal cord in sham, SCI and SCI+RA groups at 7 days after $\mathrm{SCl}$ (scale bar $=50 \mu \mathrm{m}$ ). B. Representative immunohistochemical staining and quantification of Caspase-3 of sections from the anterior horn of injured spinal cord in the different groups at 7 days after SCI (scale bar $=50 \mu \mathrm{m})$. C. Protein expressions and quantification of apoptosis related proteins (Bax, Bcl-2, Caspase-9, and Caspase-3) of segments from the injured spinal cord in the different groups at 7 days after $\mathrm{SCl}$. The results are expressed as means \pm SD from three independent experiments ( $\mathrm{n}=6$ per group). \#p $<0.05$ or \#\#p $<0.01$ vs. Sham group; ${ }^{*} p<0.05$ or ${ }^{* *} p<0.01$ vs. SCI group. 
A

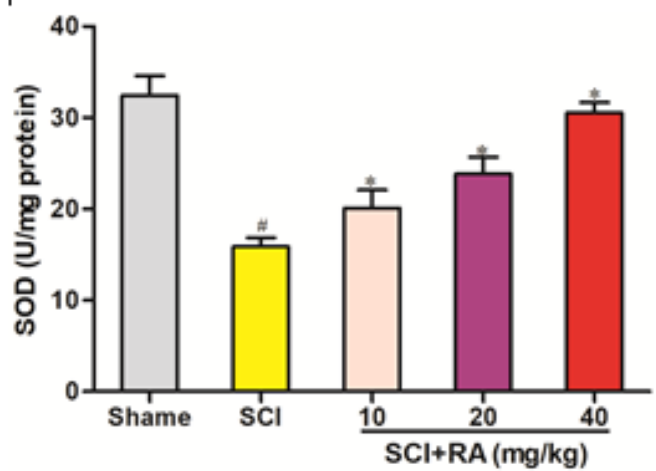

B

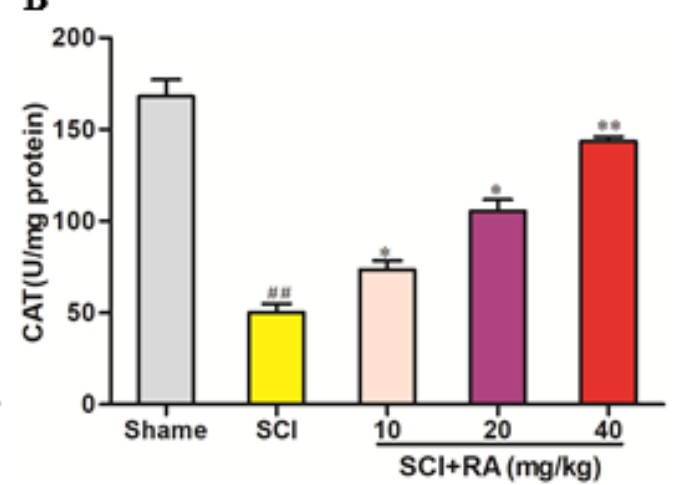

C

D
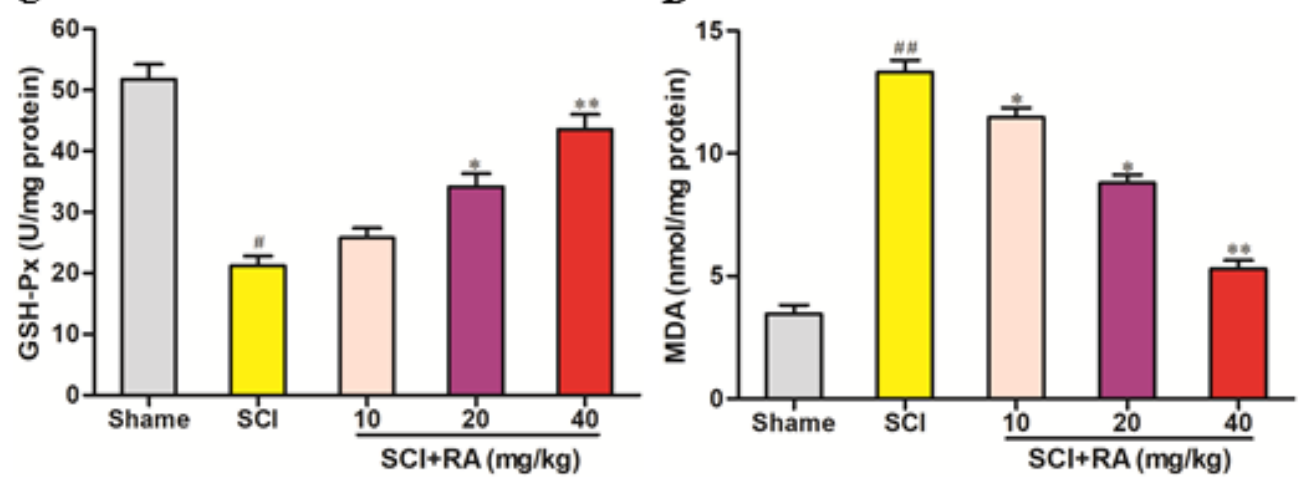

Figure 5

RA attenuated oxidative damage in spinal cord of SCl rats. Effect of RA on SOD (A), CAT (B), GSH-Px (C), and MDA (D) contents from segments of the injured spinal cord in sham, $\mathrm{SCl}$ and $\mathrm{SCl}+\mathrm{RA}$ groups at 7 days after $\mathrm{SCl}$. The results are expressed as means \pm SD from three independent experiments $(n=6$ per group). $\# p<0.05$ or \#\#p $<0.01$ vs. Sham group; ${ }^{\star} p<0.05$ or ${ }^{\star \star} p<0.01$ vs. SCl group. 

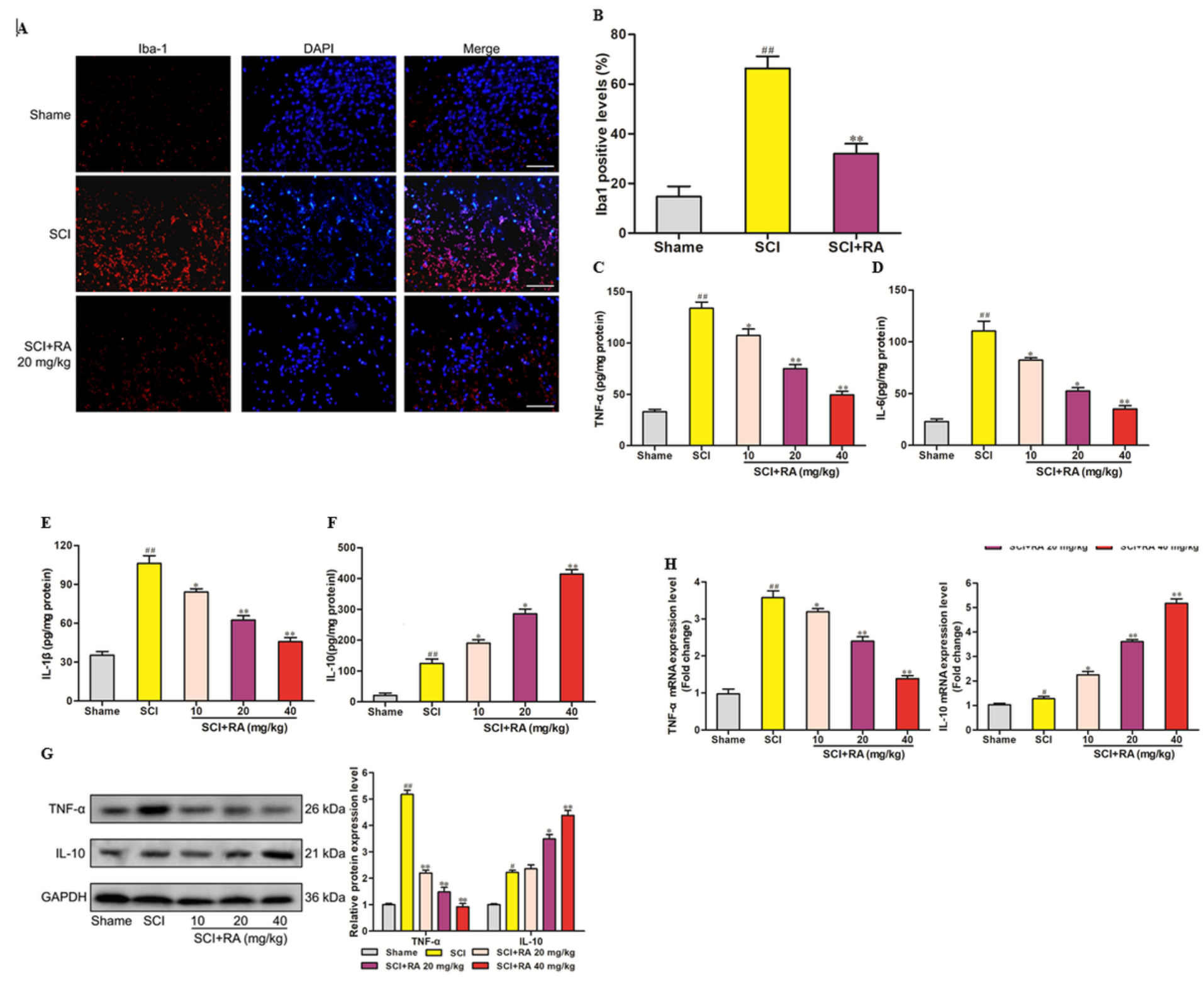

\section{Figure 6}

RA inhibited inflammatory response in spinal cord of SCI rats. A. Representative immunofluorescence images of Iba1 of sections from the anterior horn of injured spinal cord in sham, $\mathrm{SCl}$, and $\mathrm{SCl}+\mathrm{RA}$ group at 7 days after $\mathrm{SCl}$. The nuclei were stained with DAPI (blue) and the images were obtained through fluorescent microscope (magnification $\times 200$, scale bar $=50 \mu \mathrm{m}$ ). B. Quantification of the number of Iba-1-positive cells at 7 days after SCl. C-F. Effect of RA on the levels of TNF-a (C), IL-6 (D), IL-1 (E), and IL-10 (F) contents from segments of the injured spinal cord in the different groups at 7 days after $\mathrm{SCl}$. G. Protein expressions and quantification of TNF- $a$ and IL-10 from segments of the injured spinal cord in the different groups at 7 days after SCl. H. mRNA levels for TNF- $a$ and IL-10 from segments of the injured spinal cord in the different groups at 7 days after SCl. The results are expressed as means \pm SD from three independent experiments $(n=6$ per group). $\# p<0.05$ or $\# \# p<0.01$ vs. Sham group; ${ }^{\star} p<0.05$ or ${ }^{\star *} p<0.01$ vs. SCl group. 

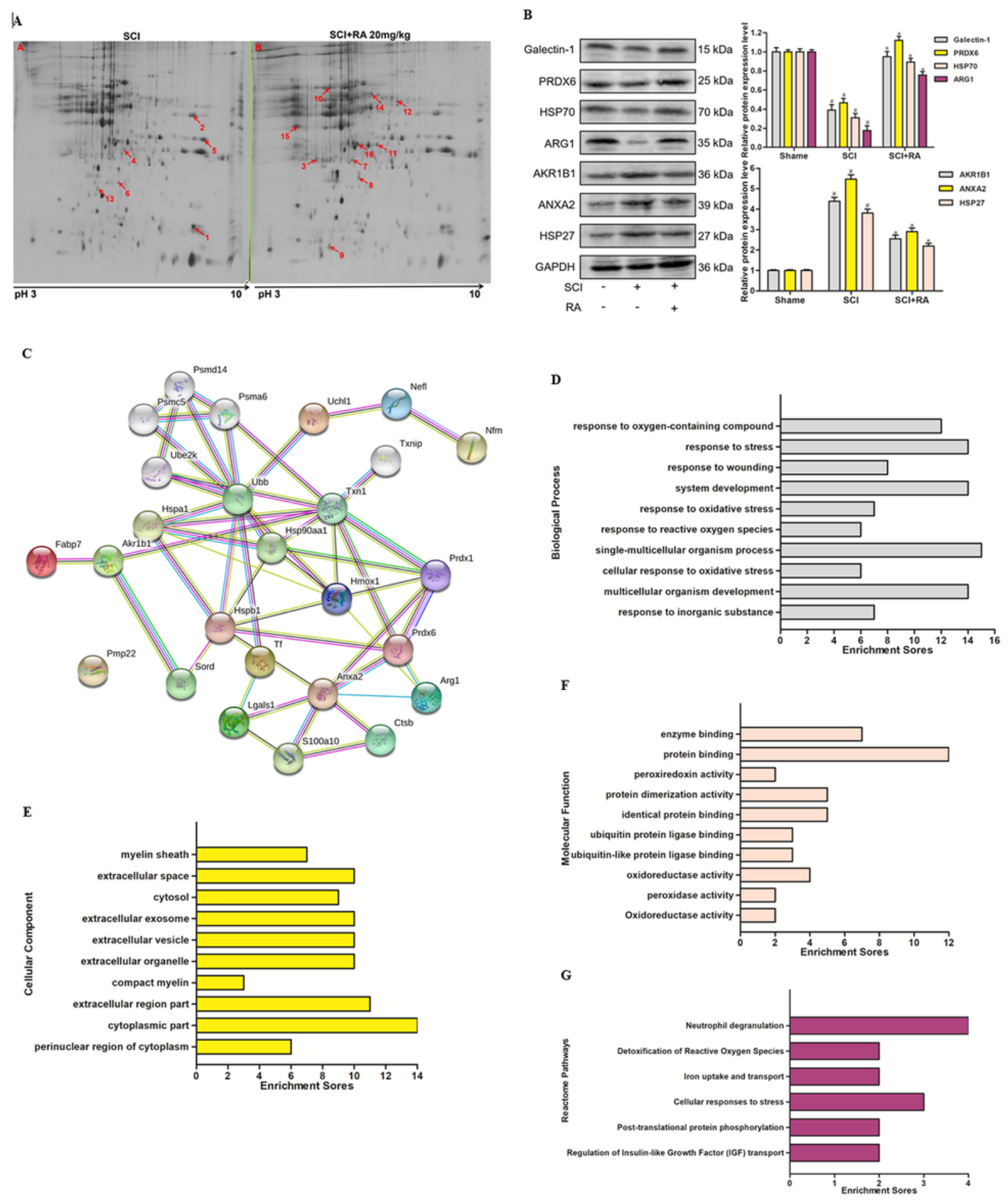

\section{Figure 7}

Representative 2-DE gels derived from spinal cord tissues after SCl with and without RA treatment, protein interaction network, and functional analyses. A. SCl rats were treated with $20 \mathrm{mg} / \mathrm{kg}$ of RA or control for 7 days. Total protein extracts were separated on $\mathrm{pH}$ 3-10 nonlinear IPG strips in the first dimension, followed by $12 \%$ SDS-PAGE in the second dimension and visualization via silver staining. Sixteen differentially expressed spots were identified by MS (marked with an arrow and number). B. Confirmation of MALDI/TOF/MS identified proteins by Western blotting in spinal cord tissues of sham, $\mathrm{SCl}$, and SCl+RA group at 7 days after SCl. GAPDH was used as the loading control. C. Protein-protein interaction networks built on STRING for the identified 
proteins. D-F. GO classification of the proteins affected by RA in SCl rats. The y-axis shows significantly enriched $\mathrm{GO}$ terms relative to the genome, and the $\mathrm{x}$-axis shows the enrichment scores of these terms. (D) MF categories in GO. (E) BP categories in GO. (F) CC categories in GO. G. Reactome pathway analysis of differentially expressed proteins associated signal pathways. The results are expressed as means \pm SD from three independent experiments ( $n=6$ per group). $\# p<0.05$ vs. Sham group; ${ }^{*} p<0.05 v$ s. $S C l$ group.

A

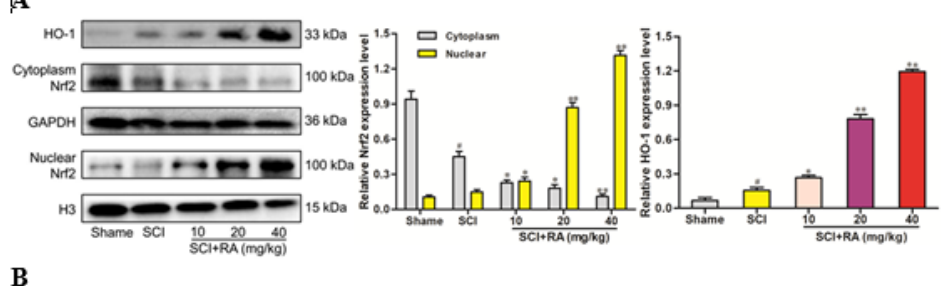

B

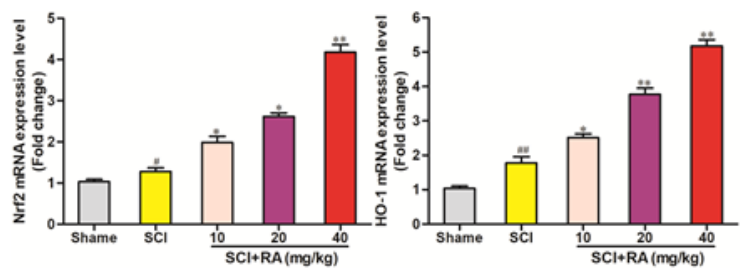

c
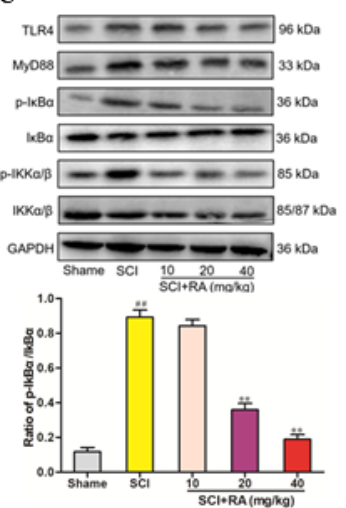
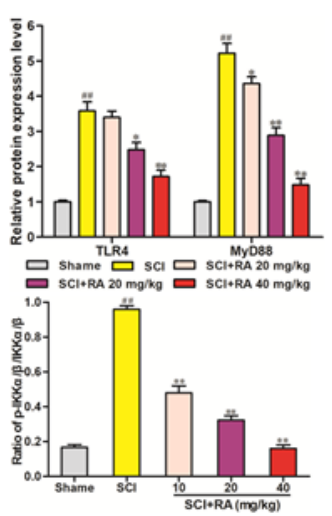

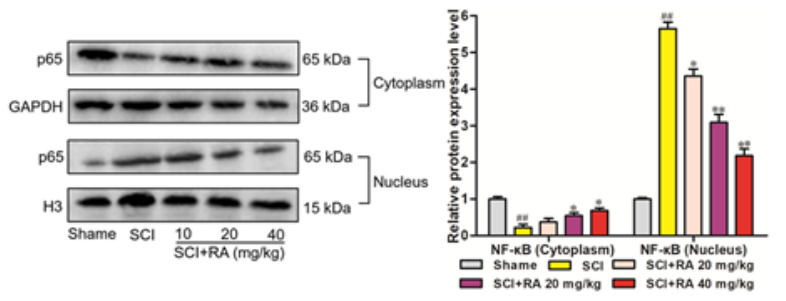

Figure 8

Intervention in the RA-induced activation of Nrf2/HO-1 and its inhibition of NF-KB signaling in rats of SCl. A. Protein expressions and quantification of $\mathrm{Nrf} 2$ and $\mathrm{HO}-1$ from segments of the injured spinal cord in sham, $\mathrm{SCl}$, and SCl+RA group at 7 days after SCl. B. mRNA levels for Nrf2 and HO-1 from segments of the injured spinal cord in the different groups at 7 days after SCl. C. Protein expressions and quantification of TLR4, MyD88, $\mathrm{p}-\mathrm{IkBa}, \mathrm{lkBa}, \mathrm{p}-\mathrm{IKKa} / \beta$ and $\mathrm{IKKa} / \beta$ from segments of the injured spinal cord in the different groups at 7 days after SCl. D. Protein expressions and quantification of cytoplasm and nucleus NF-KB-p65 from segments of the injured spinal cord in the different groups at 7 days after $\mathrm{SCl}$. The results are expressed as means $\pm \mathrm{SD}$ from three independent experiments ( $n=6$ per group). $\# p<0.05$ or \#\#p $<0.01$ vs. Sham group; ${ }^{\star} p<0.05$ or ${ }^{\star \star} p$ $<0.01$ vs. SCl group. 

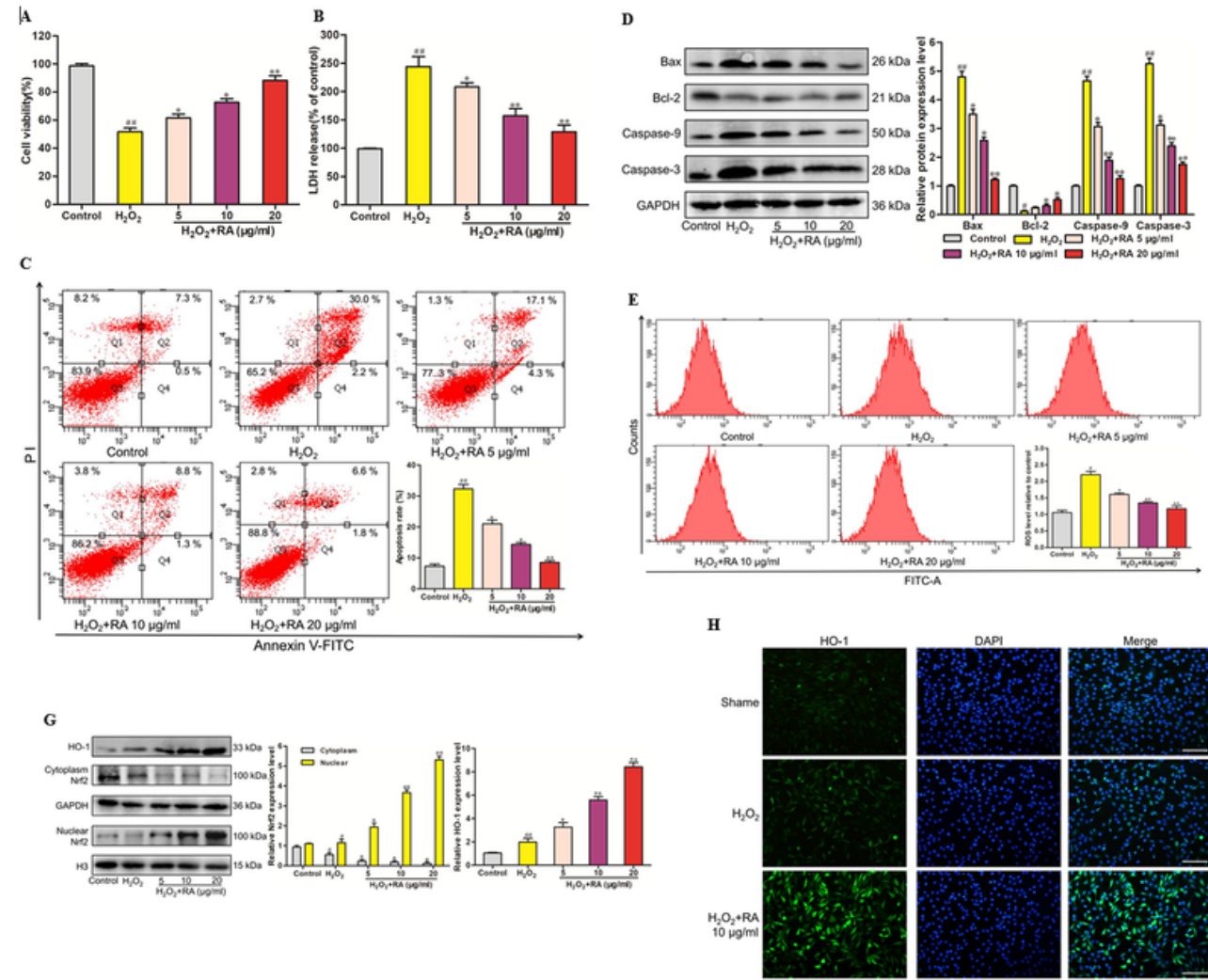
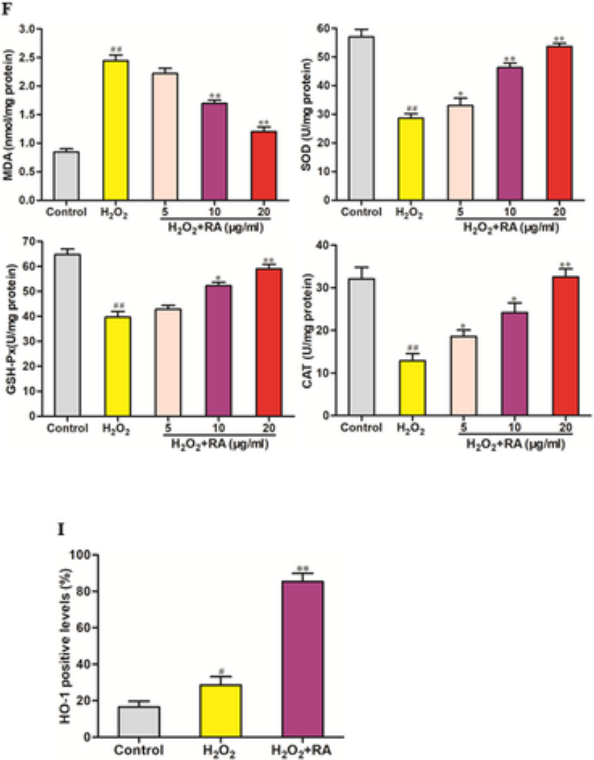

\section{Figure 9}

RA attenuated H2O2-induced oxidative injury and increased accumulation of Nrf2 in the nucleus in PC12 cells. PC1 2 cells were pretreated with different concentrations of RA $(5,10$ and $20 \mu \mathrm{g} / \mathrm{ml})$ for $24 \mathrm{~h}$ before the addition of $200 \mu \mathrm{M} \mathrm{H} 2 \mathrm{O} 2$ for $24 \mathrm{~h}$. A. cell viability was measured using the CCK-8 assay. B. Cytotoxicity was measured using the LDH release assay kit. C. Apoptotic cell rate was measured using Annexin V-FITC and PI staining assay through flow cytometry. D. The expression of apoptosis-related proteins was respectively assessed by Western blotting analysis. E. A scatter diagram of the DCFH-DA result shows the level of ROS in PC12 cells through flow cytometry. F. Effects of RA on SOD, CAT, GSH-Px, and MDA contents in PC12 cells. G. The expression of Nrf2 and HO-1 proteins was respectively assessed by Western blotting. H. Representative immunofluorescence images of HO-1 in PC12 cells at magnification of 200x (Scale bar $=50 \mu \mathrm{m}$ ). The nuclei were stained with DAPI (blue) and the images were obtained via fluorescent microscope. I. Quantification of the number of Iba1-positive cells in PC12 cells. The results are expressed as means \pm SD from three independent experiments. \#p $<0.05$ or \#\#p $<0.01$ vs. Control group; ${ }^{\star} p<0.05$ or ${ }^{\star \star} p^{p}<0.01$ vs. H2O2 group. 

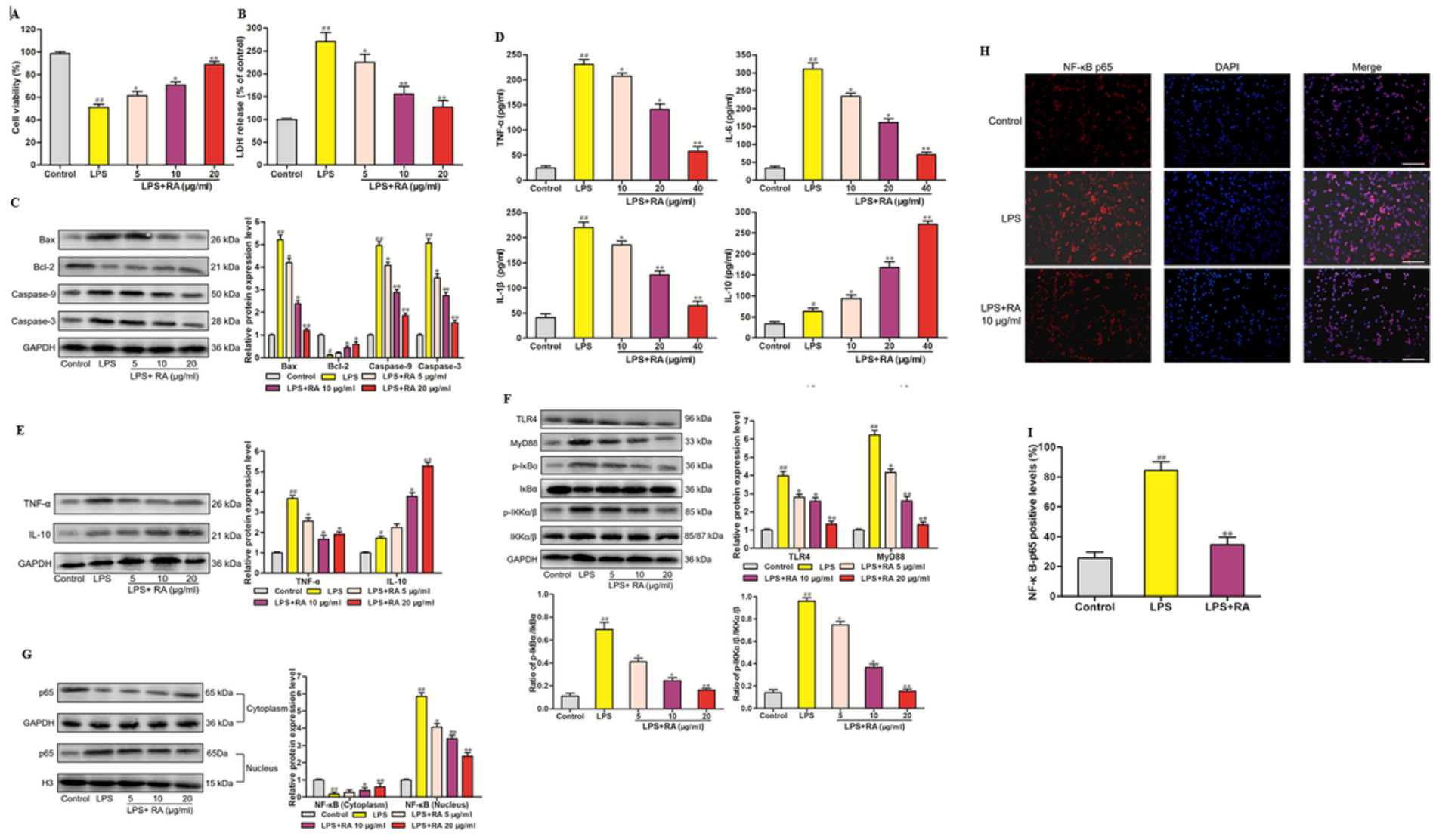

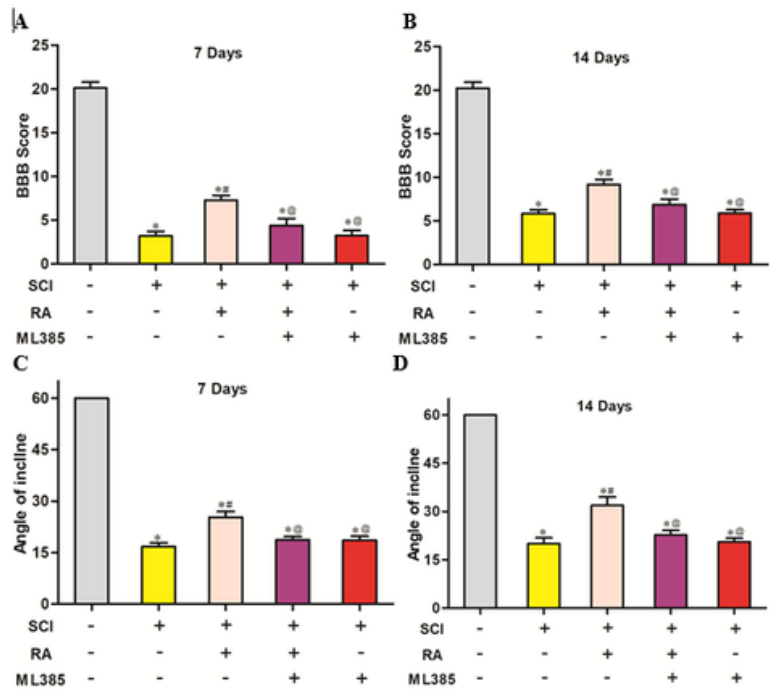

D
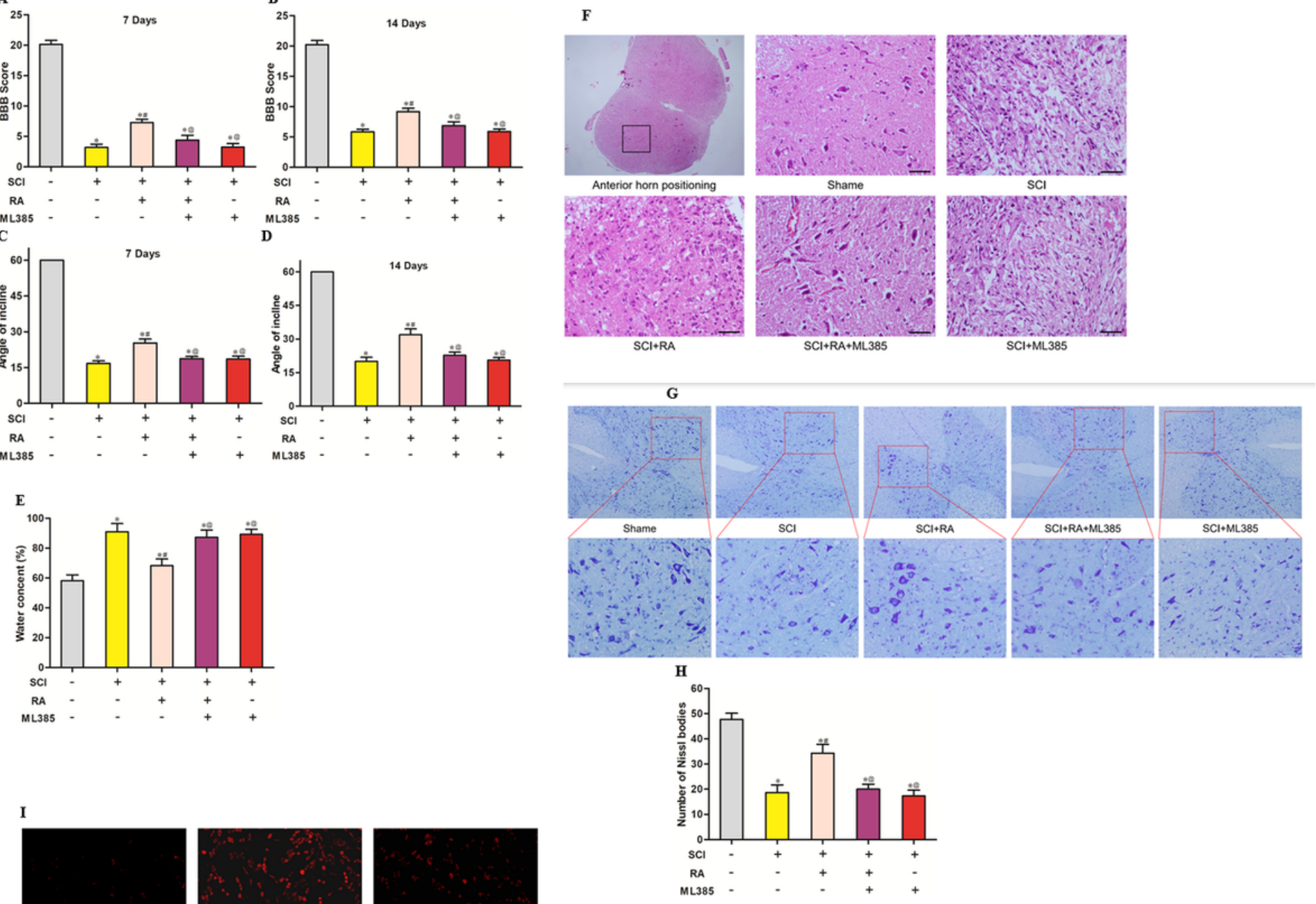

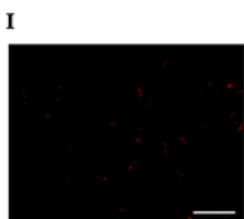

Shame

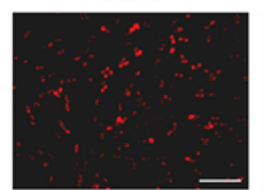

SCl+RA+ML385

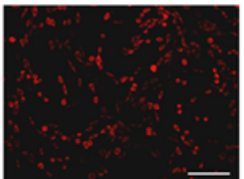

$\mathrm{SCl}$

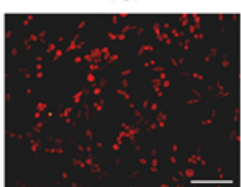

SCI+ML385

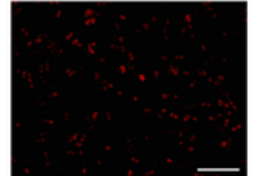

$\mathrm{SCl}+\mathrm{RA} 20 \mathrm{mg} / \mathrm{kg}$

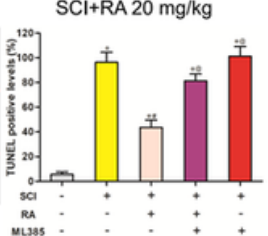

rea mas :

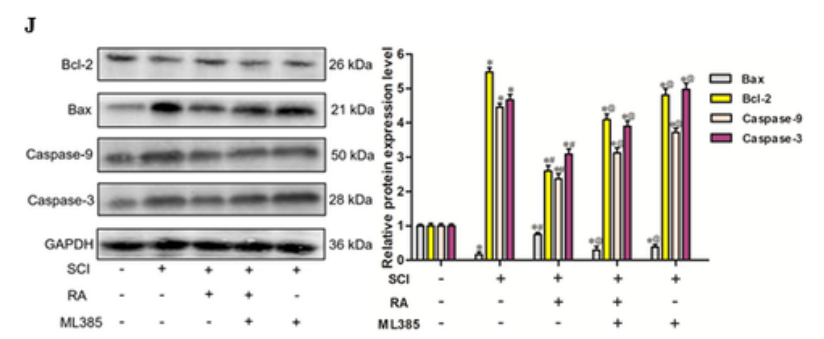

Figure 11

Blockage of Nrf2 with ML385 reversed the functional recovery and apoptosis inhibition effects of RA on SCI rats. A-B. BBB scores were calculated to evaluate the hind limb recovery at day 7 and 14 of the sham, SCl, SCl + RA, SCI + RA + ML385, and SCI + ML385 group, respectively. C-D. The inclined plane test scores were performed at day 7 and 14 of different groups. E. Effect of RA on the water content in the injured spinal cord areas in the different groups at 7 days after SCI. F. HE staining results of sections from the anterior horn of injured spinal cord in the different groups at 7 days after SCI (magnification $\times 400$, scale bar $=50 \mu \mathrm{m}$ ). $\mathrm{G}$. Representative images of Nissl staining of sections from the anterior horn of injured spinal cord in the different groups at 7 days after $\mathrm{SCl}$ (scale bar $=50 \mu \mathrm{m}$ ). Enlarged images of boxed areas are shown below. $\mathrm{H}$. Quantification analysis of the number of Nissl staining cells at 7 days after SCI. I. Representative TUNEL 
staining images and quantification of sections from the anterior horn of injured spinal cord in the different groups at 7 days after $\mathrm{SCl}$ (scale bar $=50 \mu \mathrm{m}$ ). J. Protein expressions and quantification of apoptosis related proteins (Bax, Bcl-2, Caspase-9, and Caspase-3) of segments from the injured spinal cord in the different groups at 7 days after $\mathrm{SCl}$. The results are expressed as means \pm SD from three independent experiments $(\mathrm{n}=$ 6 per group). *p < 0.05 vs. Sham group; \#p < 0.05 vs. SCl group; @p < 0.05 vs. SCl + RA group.
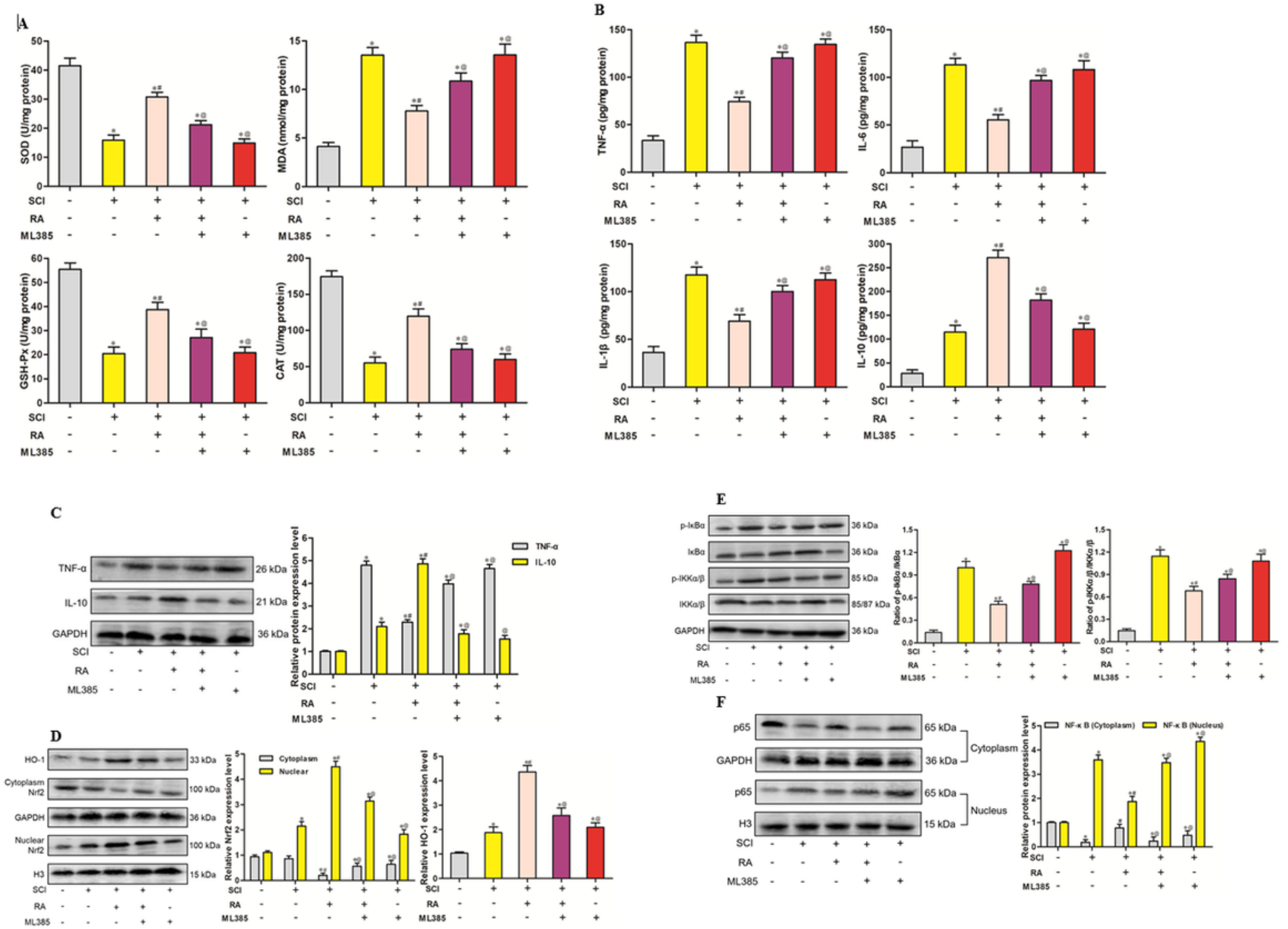

\section{Figure 12}

RA protected $\mathrm{SCl}$ rats by inhibiting oxidative stress and inflammation through modulation of the $\mathrm{Nrf2/HO}-1$ and NF-KB pathways. A. Effect of RA on SOD, CAT, GSH-Px, and MDA contents from segments of the injured spinal cord in sham, $\mathrm{SCl}, \mathrm{SCl}+\mathrm{RA}, \mathrm{SCl}+\mathrm{RA}+\mathrm{ML385}$, and $\mathrm{SCl}+\mathrm{ML} 385$ groups at 7 days after SCl. B. Effect of RA on the levels of TNF- $a$, IL-6, IL-1 $\beta$, and IL-10 contents from segments of the injured spinal cord in the different groups at 7 days after SCl. C. Protein expressions and quantification of TNF- $a$ and IL-10 from segments of the injured spinal cord in the different groups at 7 days after SCl. D. Protein expressions and quantification of TNF- $\alpha$ and IL-10 from segments of the injured spinal cord in the different groups at 7 days after SCl. E. Protein expressions and quantification of $\mathrm{p}-\mathrm{IkBa}, \mathrm{IkBa}, \mathrm{p}-\mathrm{IKKa} / \beta$ and $\mathrm{IKKa} / \beta$ from segments of the injured spinal cord in the different groups at 7 days after SCl. F. Protein expressions and quantification of cytoplasm and nucleus NF-KB-p65 from segments of the injured spinal cord in the different groups at 7 days 
after $\mathrm{SCl}$. The results are expressed as means \pm SD from three independent experiments $\left(\mathrm{n}=6\right.$ per group). ${ }^{*} \mathrm{p}<$ 0.05 vs. Sham group; \#p < 0.05 vs. SCl group; @p < 0.05 vs. SCI + RA group.

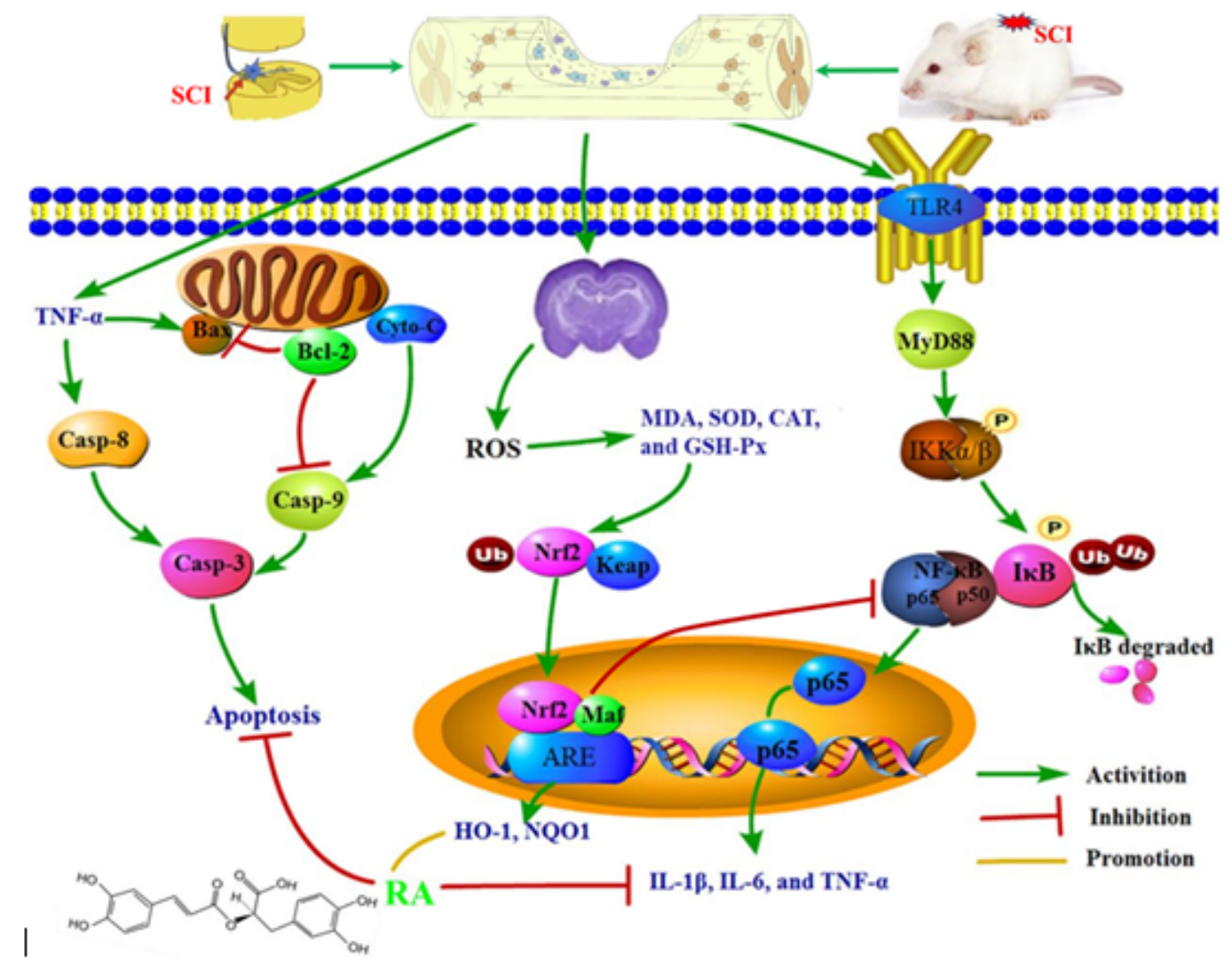

Figure 13

Proposed mechanisms of RA in protecting SCl and promoting nerve repair. RA exerts neuroprotective effect against oxidative stress and inflammation through activating the Nrf2/HO-1 signaling pathway and inhibiting the NF-KB signaling pathway in SCl rats.

\section{Supplementary Files}

This is a list of supplementary files associated with this preprint. Click to download.

- Supplementarydata.docx 